\title{
Pyroshock Acceleration Field Reconstruction in Temporal and Spectral Domains Based on Laser Shock Scanning and Iterative Decomposition and Synthesis Considering Stop Band Effects
}

\author{
Yong-Woon Kim, Jae-Kyeong Jang, and Jung-Ryul Lee \\ Department of Aerospace Engineering, Korea Advanced Institute of Science and Technology, Daejeon, Republic of Korea \\ Correspondence should be addressed to Jung-Ryul Lee; leejrr@kaist.ac.kr
}

Received 31 May 2017; Revised 25 August 2017; Accepted 17 September 2017; Published 26 October 2017

Academic Editor: Vadim V. Silberschmidt

Copyright ( 12017 Yong-Woon Kim et al. This is an open access article distributed under the Creative Commons Attribution License, which permits unrestricted use, distribution, and reproduction in any medium, provided the original work is properly cited.

\begin{abstract}
Pyrotechnic devices are used to separate substructures from main structures. Pyroshock can cause failure in electronic components that are sensitive to high frequency shock. Most of the existing methods to analyze pyroshock have limitations for high frequency simulations and are only available for simulation of point explosive-induced pyroshock. To solve the problem of existing methods, we developed a laser shock-based pyroshock reconstruction algorithm covering high frequency range that can predict linear explosive-induced pyroshock, as well as point explosive-induced ones. The developed algorithm reconstructs pyroshock from laser shock test in both temporal and spectral domains using an iterative signal decomposition and synthesis method. In the signal decomposition and synthesis process, unremoved signals in the stopbands occurred and were compensated by iteration to improve the results. At the end of this paper, various types of pyroshock were processed through the proposed method. Pyroshock wave propagation images and shock response spectrum images were presented as a result. To verify the algorithm, we compared the obtained result with a real pyroshock. The time domain signal was reconstructed with an averaged peak to peak acceleration difference of $20.21 \%$, and the shock response spectrum was reconstructed with an average mean acceleration difference of $25.86 \%$.
\end{abstract}

\section{Introduction}

Pyrotechnic devices are used to separate substructures from main structures in such situations as vehicle launches, rocketstage separations, missile launches, and pilot ejections [13]. Pyrotechnics have advantageous features, such as high energy per unit weight and volume [4]. These features have ensured that pyrotechnic devices are widely used in aerospace structures. On the other hand, pyrotechnics have a critical safety problem. During operation, high acceleration and high frequency structural shock, called pyroshock, always occur. Pyroshock rarely influences structural members, but its high frequency characteristic can easily cause failure in electronic components [5]. In a NASA technical memorandum, Laurence described a survey compiled over a 23-year period, which included 84 serious component or system failures. Out of the failures, 12 occurred in-flight with fully developed and qualified hardware [6]. Therefore, it is necessary to evaluate the pyroshock transmitted to the structure and to predict the damage of the electronic equipment.

Previous research implemented pyroshock using real pyro devices that downscaled structures. This technique had the advantage of being capable of simulating pyroshock in the most reasonable fashion. However, since the actual pyro device was used, the structures were damaged and could not be used again. Therefore, it was necessary to manufacture the respective structures separately for all the experiments, so that the economic burden and time were inevitable [79]. Because of problems with cost and safety, pyroshock imitation techniques using mechanical impact instead of pyro devices were studied. This technique simulates pyroshock by causing mechanical collisions using pendulum motion. These tests yielded excellent simulation results in the mid-field and far-field, but simulation results were not good in the nearfield [10-12]. 
In addition, previous studies that simulated pyroshock using numerical analysis were reviewed. Among them, recent research into Hydro-code-based pyroshock simulation has been reported as suitable for simulating highly dynamic phenomena such as pyroshock [13-15]. However, most of these numerical techniques required accurate knowledge of all parameters of the structure to obtain reliable simulation results, and computational time and cost limitations emerged when applied to complex structures $[16,17]$.

Recently, laser shock has been used to reconstruct pyroshock in [18]. The pyroshock reconstruction method, using laser shock, had the advantage that it could confirm propagation of pyroshock in real structure nondestructively. Since shock generating and measuring processes are distinct, there are characteristic differences between laser shock and pyroshock, even though both are elastic wave in solid medium. In [18], the reconstructed results has used an algorithm that only adjusts the peak value to compensate for this characteristic difference. This resulted in a below average reconstruction response. In [19], Chong has reconstructed pyroshock by statistically predicting how the amplitude of the pyroshock changes with distance from the shock source and provided the predicted information to the laser shock. However, since the pyroshock not only is dependent on the distance from the explosion source but also depends on the geometry of the structure, the algorithm developed in [19] was able to reconstruct only on the simple specimens. Therefore, to reconstruct pyroshock using the laser shock, an innovative algorithm that can appropriately compensate for the characteristic difference between the two shocks is needed.

In this paper, we present a novel algorithm to reconstruct the waveform and spectrum response of pyroshock and laser shock for both linear and point-wise pyrotechnical devices to overcome the limitations of existing laser shock-based methods. The proposed algorithm compensates for the difference in characteristics of laser shock and pyroshock by using the iterative signal decomposition and synthesis method, which achieved the gain needed to compensate for the difference in characteristics between laser shock and pyroshock based on shock response spectrum (SRS). The gain was applied to laser shock signal decomposition via Butterworth filter in each frequency band. In the laser shock decomposition process, due to the inevitable characteristics of the band-pass filter, the decomposed signal in the passband included the unwanted signals that in-flowed from stopbands. This is an interference problem that was compensated by iteratively removing the unwanted signal to improve the reconstruction result.

The reconstruction results are presented using the proposed pyroshock wave propagation imaging (PWPI) and shock response spectrum imaging (SRSI) algorithms. We can validate propagation characteristics such as propagation path and reflection waves of pyroshocks based on PWPI results in the time-space domain and determine how much the structure is affected by the pyroshock for each frequency using the SRSI results. To verify the proposed algorithm, the comparison results with the real pyroshock are presented in terms of similarity between the real pyroshock and reconstructed pyroshock.

\section{Simultaneous Temporal and Spectral Pyroshock Reconstruction Algorithm}

Figure 1 shows the flow chart of the pyroshock reconstruction algorithm developed in this paper. The algorithm is divided into 5 steps. In the first step, real pyroshock signals are measured using LDV sensors. In the second step, laser shock signals generated by Q-switch laser are acquired through a PZT sensor. In the third step, the shock response spectrum (SRS) of the pyroshock is reconstructed by compensating the characteristic difference between the laser shock and pyroshock. In the fourth step, the signal decomposition and synthesis method is used to reconstruct the time domain signal of pyroshock by giving the information of the reconstructed SRS to laser shock data. In the fifth step, PWPI and SRSI are generated using the reconstructed pyroshock data. The details of each step are explained in the following sections.

2.1. Real Pyroshock Measurement at Multipoints. The pyroshock measurement is performed through a shock measurement system based on multiple laser Doppler vibrometers (LDVs, Polytech Inc.) as shown in Figure 2. First, the target structure and the pyro devices are installed and the area to be analyzed is specified. The point at which you want to acquire the pyroshock is determined and the coordinates of that point are indicated by $\left(x_{s}, y_{s}\right)$. Finally, we set up the DAQ configuration through the GUI platform and wait for the pyro device to explode. Then, when the pyro device is exploded, pyroshock signals are collected from the LDV sensor according to the DAQ condition set through the GUI platform. The pyroshock signals collected from the sensors are stored in the PC as digital voltage form. The pyroshock signal is stored in the digital voltage form and is denoted by $V_{D}\left(x_{s}, y_{s}, t\right)$. It is then calibrated to the pyroshock signal $P\left(x_{s}, y_{s}, t\right)$ of the acceleration unit through a conversion process using (1).

$$
\begin{aligned}
P & \left(x_{s}, y_{s}, t\right) \\
& =\left[\frac{d\left(V_{D}\left(x_{s}, y_{s}, t\right) \times \mathrm{CF} \times 10^{A_{\mathrm{dB}} / 20} \times \mathrm{CF}_{\mathrm{mr}}\right)}{d t}\right],
\end{aligned}
$$

where $V_{D}\left(x_{s}, y_{s}, t\right)$ is pyroshock signal of digital voltage form [V]. $P\left(x_{s}, y_{s}, t\right)$ is pyroshock signal of acceleration unit [g]. $\mathrm{CF}$ is calibration factor of LDV sensor. $A_{\mathrm{dB}}$ is attenuation factor of attenuator. $\mathrm{CF}_{\mathrm{mr}}$ is measurement unit of $\mathrm{LDV}$ sensor $[\mathrm{m} / \mathrm{s} / \mathrm{V}]$.

2.2. Laser Shock Scanning Measurement. Through the pyroshock measurement process, we can observe the characteristics of the pyroshock. However, since the number of LDV sensors is limited, pyroshock can be detected only at a few limited points. To confirm the propagation of pyroshock for the whole structure, we reconstruct pyroshock using laser shock. First, the same structure used in the pyroshock measurement is prepared to obtain the laser shock signal. Then, PZT sensors (R-Cast M204A, Fuji ceramics Inc.) are installed in place of the pyrotechnical device because the 


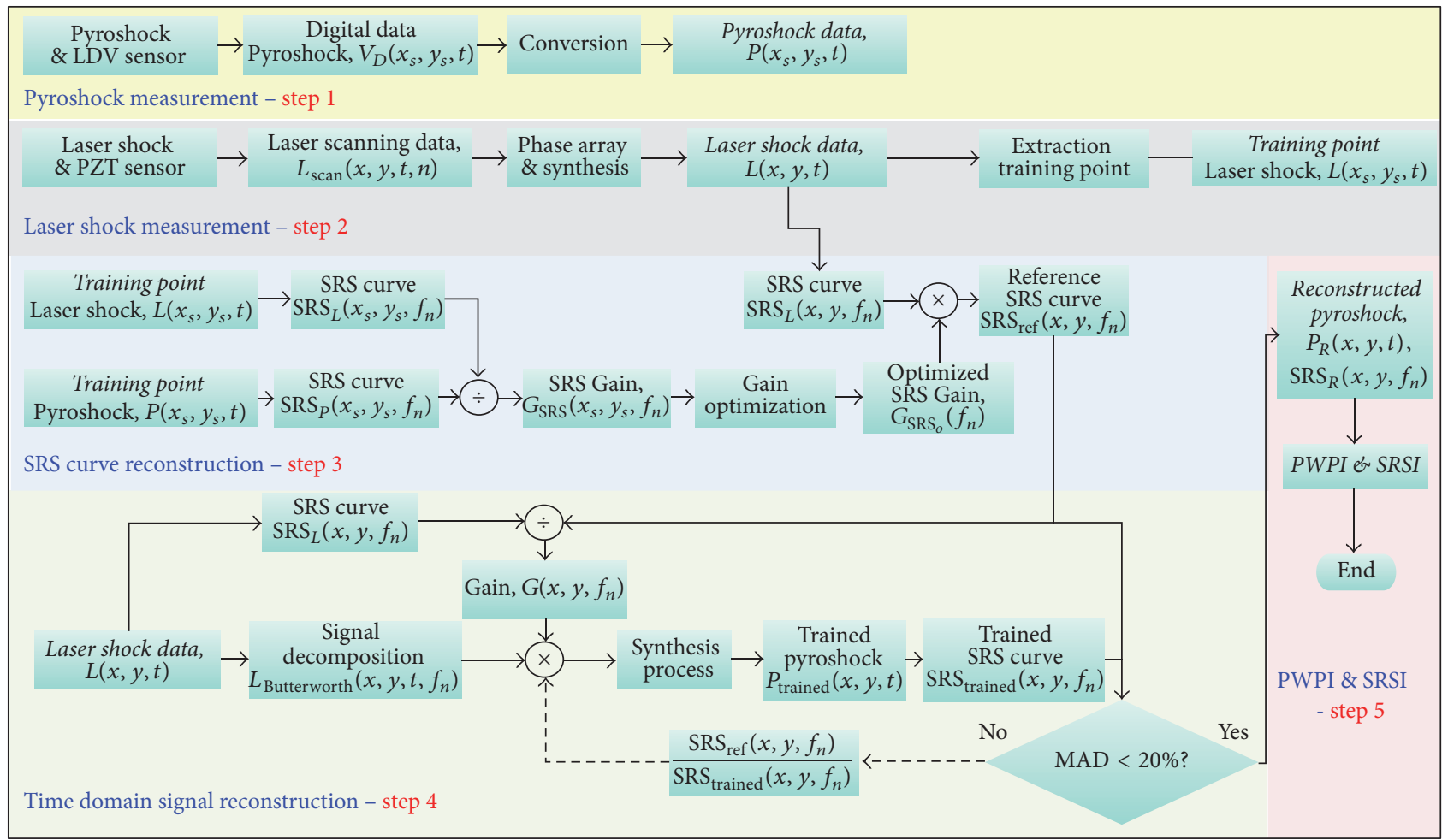

FIGURE 1: Flow chart of pyroshock reconstruction algorithm based on laser shock.

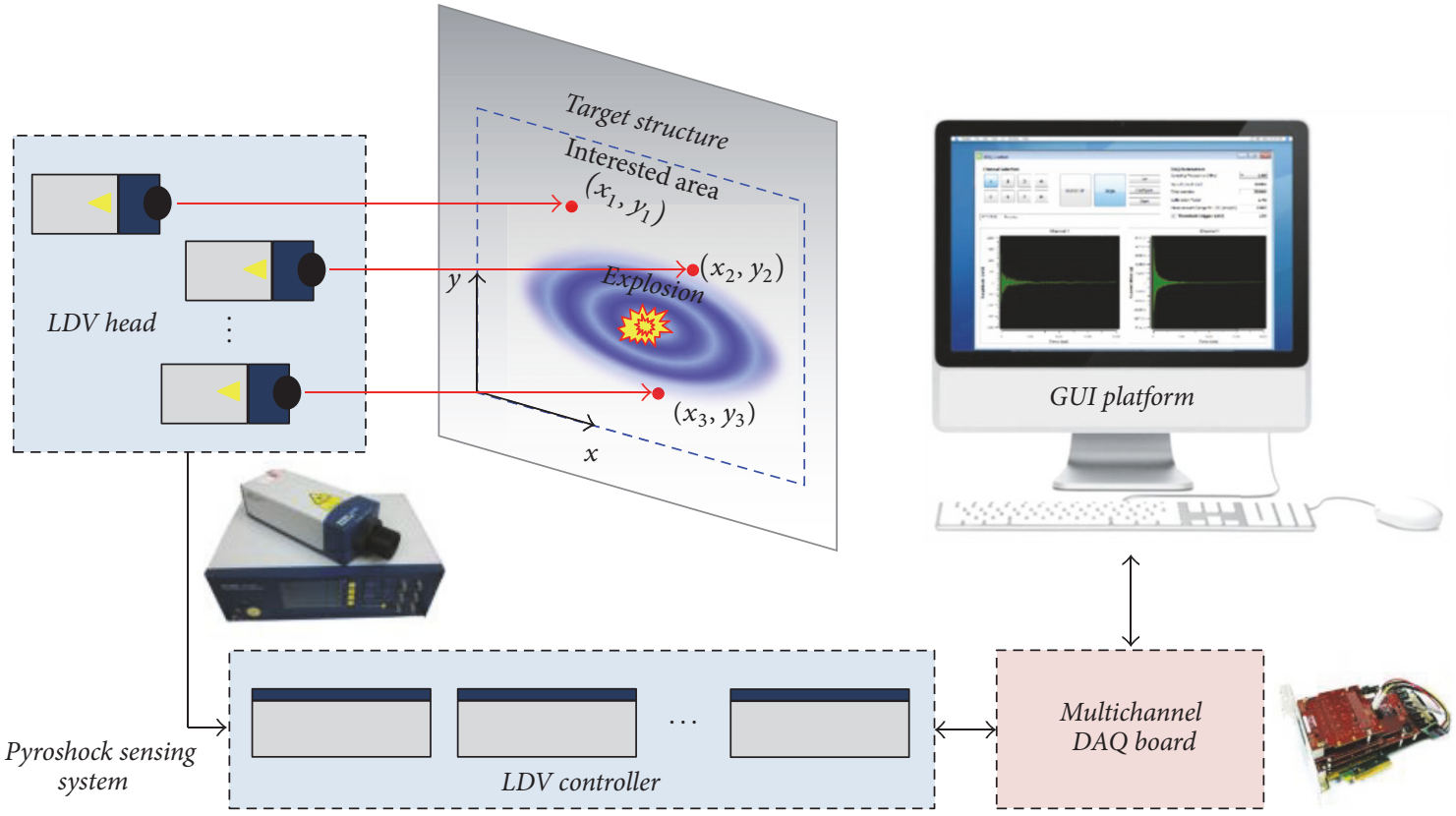

FIGURE 2: Pyroshock measurement process using a shock measurement system based on multiple laser Doppler vibrometers (LDVs).

reciprocal setup of the laser shock scanning system (Mobile PZT-UPI, X-NDT Inc.) designates the sensor locations shock source locations. Once the structure and sensors are installed, the laser scanning process proceeds as shown in Figure 3. The GUI platform, shown in Figure 3(a), sets the DAQ conditions and transmits commands to the Q-switch laser and the laser mirror scanner. The laser mirror scanner moves the laser along the scan path. The laser beam moves through the laser mirror scanner and generates the laser shock at the position where it will stay, as shown in Figure 3(b). The laser shock is generated as shown in Figure 3(c). It is collected through a PZT sensor and subsequently stored in a PC. When 


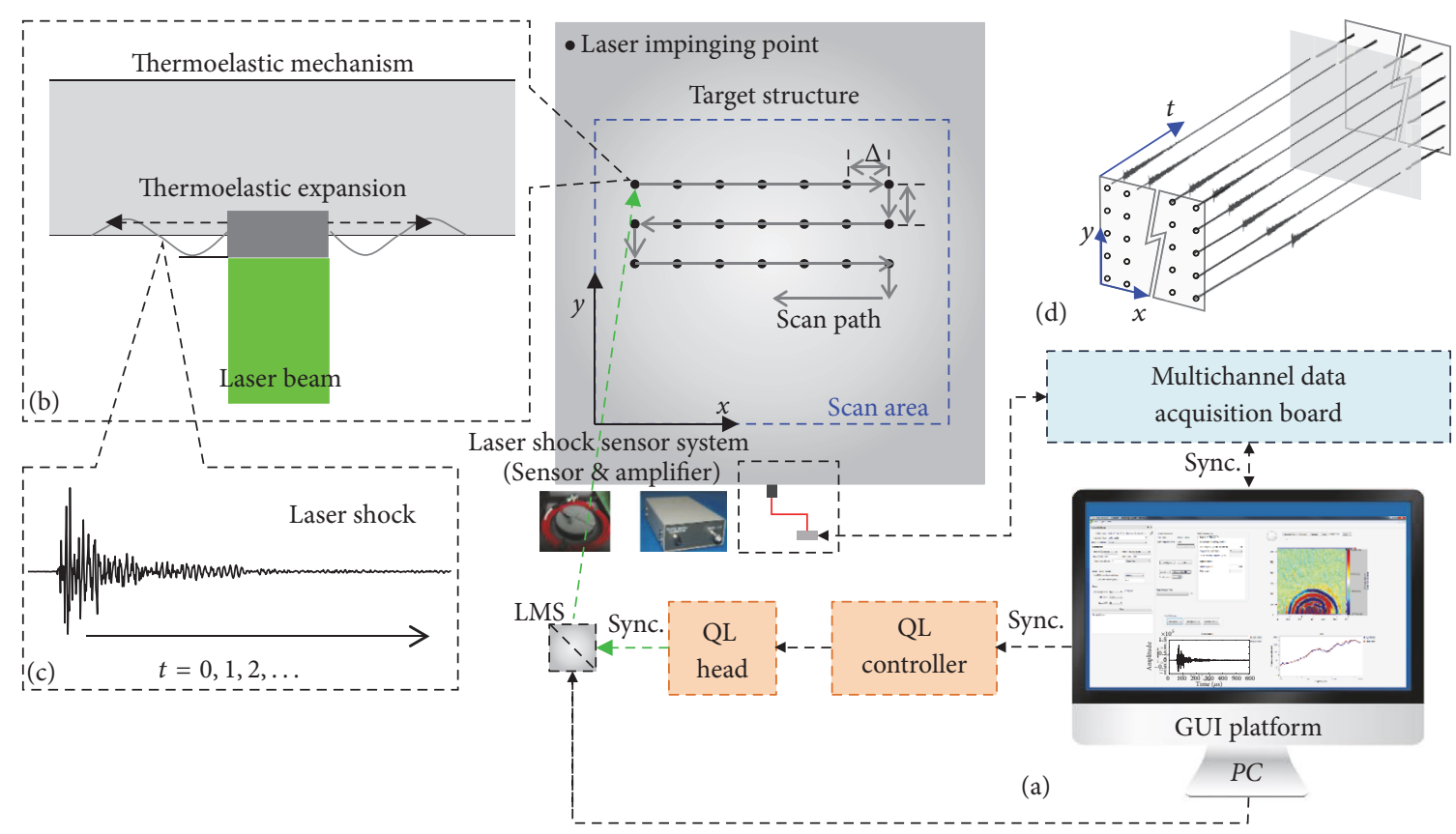

FIGURE 3: Laser shock measurement process scheme; (a) PC with GUI platform. (b) Thermoelastic mechanism. (c) Laser shock time domain signal. (d) Laser scanning data.

the laser scanning process is completed, four-dimensional laser shock data are obtained as shown in Figure 3(d). The obtained laser shock data are denoted by $L(x, y, t)$. If the pyroshock is not induced by a single point source but is induced by a combined explosion such as linear explosive induced pyroshock, the wave superposition principle is used under the assumption that the structural response to the pyroshock is linear. Many PZT sensors are placed at the site of the combined explosion, and laser shock data are acquired from each sensor. The laser scanning data obtained from each sensor are denoted as $L_{\text {scan }}(x, y, t, n)$. To simulate pyroshock induced by combined explosion sources, $L_{\text {scan }}(x, y, t, n)$ is phase arrayed and superimposed according to the explosion mechanism. The superimposed result is denoted as $L(x, y, t)$. In $L(x, y, t)$, the data at the same point as the point at which the pyroshock was measured is designated $L\left(x_{s}, y_{s}, t\right)$.

2.3. Shock Response Spectrum Reconstruction. To reconstruct the pyroshock using laser shock, it is necessary to compensate the characteristic differences between laser shock and pyroshock. The compensation procedure is based on the SRS. The SRS is the most widely used function to quantify pyroshock and is calculated based on the time domain signal. It applies the time domain signal as a base excitation to an array of single degree of freedom (SDOF) systems [21], where the independent variable is the natural frequency. Therefore, the calculation is performed on multiple independent SDOF systems. Any arbitrary set of natural frequencies can be used for the SRS calculation. However, the typical method is based on a proportional bandwidth such as $1 / 12$ octave. Therefore, in this paper, the SRS is obtained at 1/12 octave intervals. The detailed procedure for calculating the SRS is described in [22]. Using the obtained $P\left(x_{s}, y_{s}, t\right)$ and $L\left(x_{s}, y_{s}, t\right)$, we calculate the SRS and define the results as $\operatorname{SRS}_{P}\left(x_{s}, y_{s}, f_{n}\right)$ and $\operatorname{SRS}_{L}\left(x_{s}, y_{s}, f_{n}\right)$, respectively. The ratio of the two SRSs is defined as $G_{\mathrm{SRS}}\left(x_{s}, y_{s}, f_{n}\right)$.

$$
G_{\text {SRS }}\left(x_{s}, y_{s}, f_{n}\right)=\frac{\operatorname{SRS}_{P}\left(x_{s}, y_{s}, f_{n}\right)}{\operatorname{SRS}_{L}\left(x_{s}, y_{s}, f_{n}\right)} .
$$

In the system, $G_{\mathrm{SRS}}\left(x_{s}, y_{s}, f_{n}\right)$, the value that best compensates the difference between the laser shock and the pyroshock on average, for the whole set of training points, is designated $G_{\mathrm{SRS}, O}\left(f_{n}\right)$. By multiplying the system $G_{\mathrm{SRS}, \mathrm{O}}\left(f_{n}\right)$ by $\operatorname{SRS}_{L}\left(x, y, f_{n}\right)$, the SRS reconstruction process is completed. The value obtained through the SRS reconstruction process is defined as $\operatorname{SRS}_{\mathrm{ref}}\left(x, y, f_{n}\right)$.

$$
\operatorname{SRS}_{\text {ref }}\left(x, y, f_{n}\right)=\operatorname{SRS}_{L}\left(x, y, f_{n}\right) * G_{\mathrm{SRS}, \mathrm{O}}\left(f_{n}\right) .
$$

The similarity between any two SRSs is represented by MAD. The MAD can be obtained from [20]

$$
\begin{aligned}
\operatorname{MAD}(\%)= & \left(\frac{1}{z} \sum_{f_{n}=f_{1}}^{f_{z}}\left|\frac{\mathrm{SRS}_{1}\left(f_{n}\right)-\mathrm{SRS}_{2}\left(f_{n}\right)}{\operatorname{SRS}_{1}\left(f_{n}\right)}\right|\right) \\
& * 100 \%
\end{aligned}
$$

2.4. Time Domain Signal Reconstruction. The time domain signal of the pyroshock is reconstructed by substituting $\operatorname{SRS}_{\text {ref }}\left(x, y, f_{n}\right)$ to the time domain signal of the laser shock. The reconstruction of time domain signal is based on signal decomposition and synthesis. Signal decomposition is conducted via a 2 nd order Butterworth filter with a zero-phase filter, which is a type of signal processing filter designed to have a very flat frequency response in the passband. Figure 4 

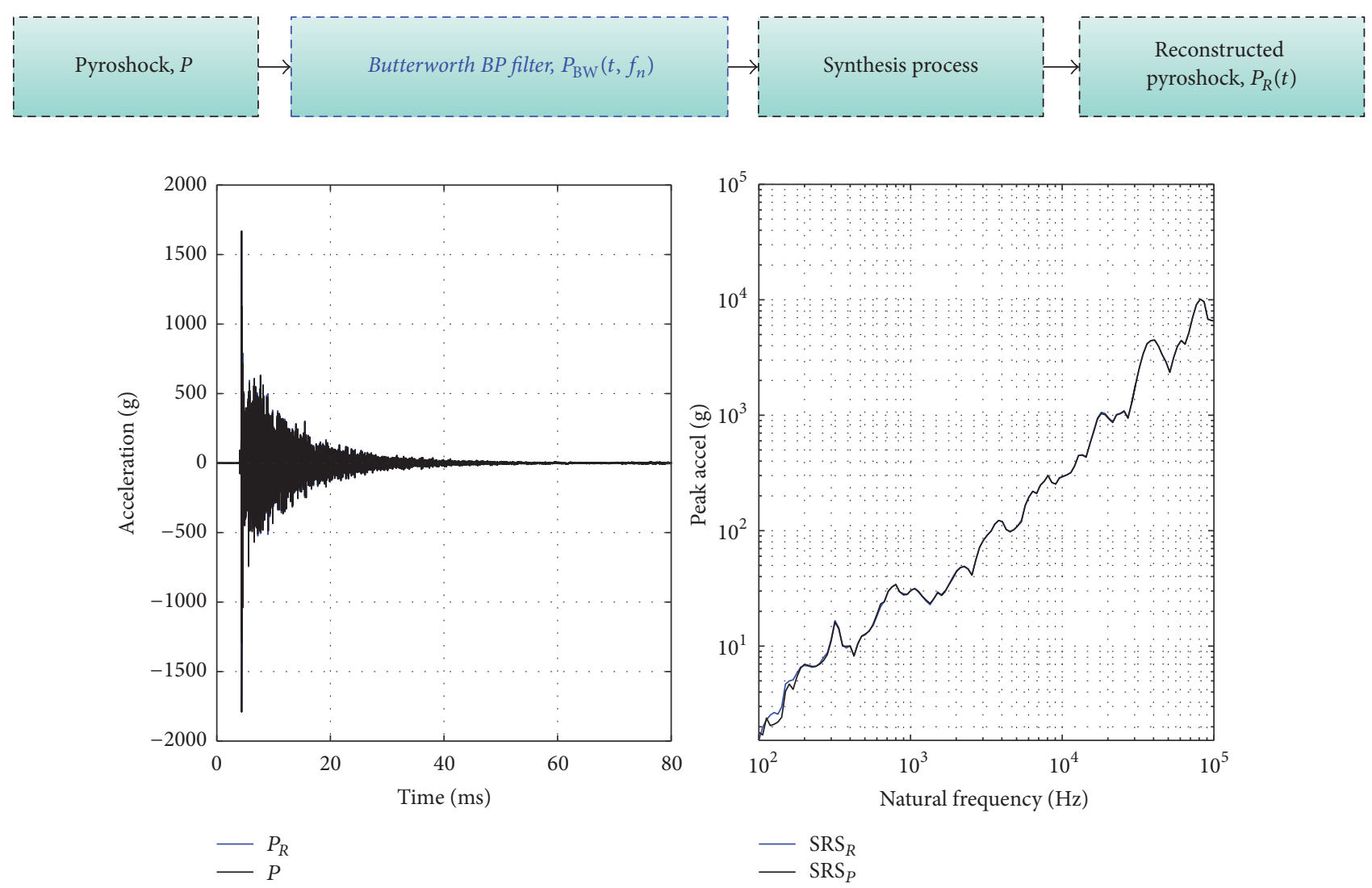

FIGURE 4: Signal decomposition and synthesis using Butterworth band-pass filter.

shows the results of signal decomposition and synthesis for arbitrary shock using Butterworth filter. The black signal represents the original signal and the blue signal represents the reconstructed signal after signal decomposition and synthesis using a Butterworth filter, which was suitable for the signal decomposition and synthesis since the original signal and the reconstructed signal were almost identical. Figure 5(a) shows a test algorithm that uses the signal decomposition and synthesis method. The gain needed to compensate for the difference between pyroshock and laser shock was obtained in the SRS domain. Then the gain was applied to a laser shock signal decomposed by Butterworth filter as shown in Figure 5(a). Figure 5(b) shows the result of the test algorithm. The blue signal shows reconstructed pyroshock and the black signal shows the real pyroshock. As shown in Figure 5(b), the reconstruction was not performed well because of the filter's problem. Since the Butterworth filter is not ideal filter, decomposed signal contains unwanted signals. For example, Figure 5(c) shows the laser shock signal decomposed between $100 \mathrm{~Hz}$ and $106 \mathrm{~Hz}$, via the Butterworth filter. It could be seen that unremoved high frequency components in the stopbands were mixed. These unremoved signals in the stopbands cause interference in the passband signals and ruin reconstruction results. To solve this stopband effect in band-pass filtering, the iteration method was applied as shown in Figure 6(a). As a result, we could obtain significantly improved results as shown in Figure 6(b). Finally, we designed the reconstruction algorithm of time domain signal as shown in Figure 7 by applying $\operatorname{SRS}_{\text {ref }}\left(x, y, f_{n}\right)$ obtained in Section 2.3 to the algorithm of Figure 6(a). First, we calculate the ratio of $\operatorname{SRS}_{L}\left(x, y, f_{n}\right)$ and $\operatorname{SRS}_{\text {ref }}\left(x, y, f_{n}\right)$ in each frequency domain as shown in Figure 7 and store it as a gain value. Next, the laser shock signal is decomposed by each frequency range using a Butterworth filter. The decomposed laser shock signal is denoted by $L_{\mathrm{BW}}\left(x, y, t, f_{n}\right)$ and the previously stored gain result is applied. After applying the gain, $P_{\text {trained }}(x, y, t)$ was obtained by synthesizing $L_{\mathrm{BW}}\left(x, y, t, f_{n}\right)$ again as (5). Finally, the interference problem of the unremoved signal in the laser shock decomposition process is compensated for by iteration. The compensation process is based on (5); the gain is updated by feedback of the stop band effect as shown in Figure 7. This process is repeated until the MAD value between $\operatorname{SRS}_{\text {ref }}\left(x, y, f_{n}\right)$ and $\operatorname{SRS}_{\text {trained }}\left(x, y, f_{n}\right)$ is less than $20 \%$. If $\operatorname{SRS}_{\text {trained }}\left(x, y, f_{n}\right)$ is sufficiently similar to $\operatorname{SRS}_{\text {ref }}\left(x, y, f_{n}\right), P_{\text {trained }}(x, y, t)$ and $\operatorname{SRS}_{\text {trained }}\left(x, y, f_{n}\right)$ are stored as $P_{R}(x, y, t)$ and $\operatorname{SRS}_{R}\left(x, y, f_{n}\right)$.

$$
\begin{aligned}
& P_{R}(x, y, t)=\sum_{f_{n}=100}^{F s / 2}\left[L_{\mathrm{BW}}\left(x, y, t, f_{n}\right)\right. \\
& \left.\cdot \frac{\operatorname{SRS}_{\mathrm{ref}}\left(x, y, f_{n}\right)}{\operatorname{SRS}_{L}\left(x, y, f_{n}\right)}\left(\prod \frac{\operatorname{SRS}_{\text {ref }}\left(x, y, f_{n}\right)}{\operatorname{SRS}_{\text {trained }}\left(x, y, f_{n}\right)}\right)\right] .
\end{aligned}
$$




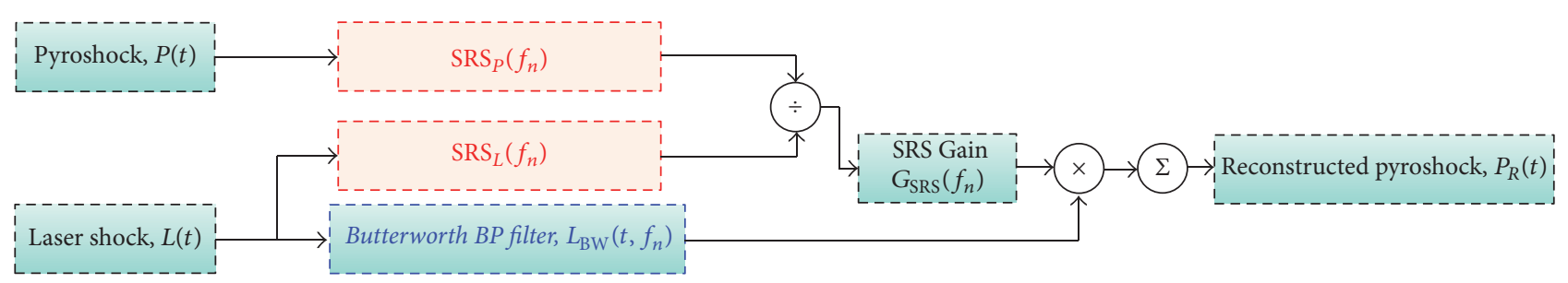

(a)

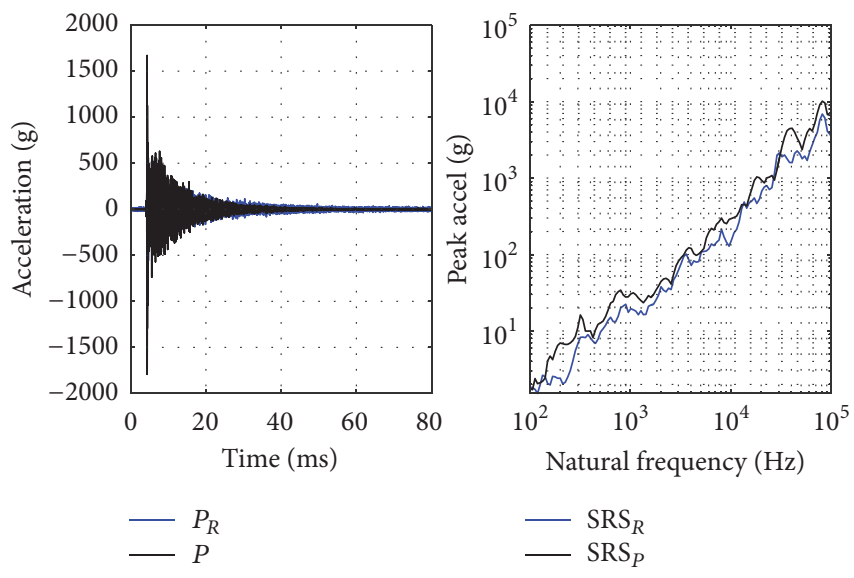

(b)
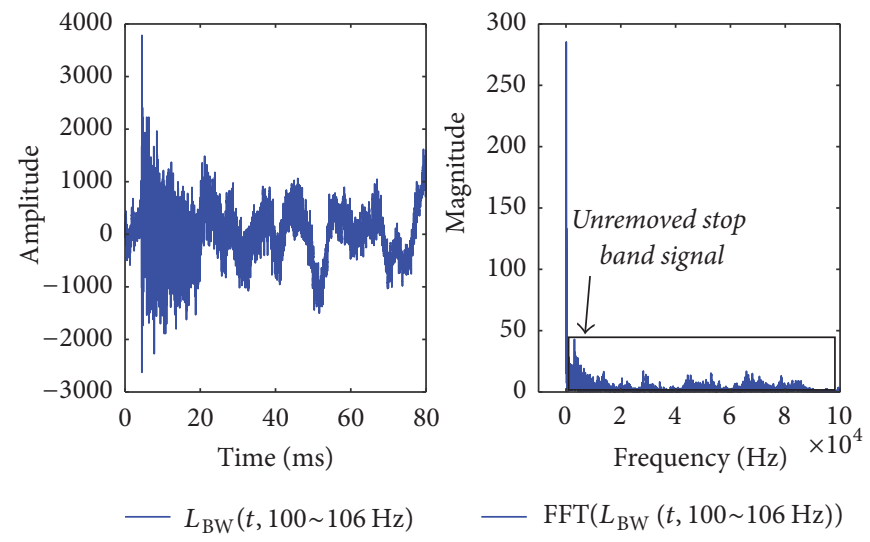

(c)

FIgURE 5: (a) Test algorithm. (b) Reconstruction results of the test algorithm. (c) The problems of test algorithm.

2.5. Pyroshock Wave Propagation Image and Shock Response Spectrum Image. When the amplitude of $P_{R}(x, y, t)$, obtained from the previous process is plotted in color scale over time, the PWPI is obtained as shown in Figure 8(a). In addition, when the amplitude of $\operatorname{SRS}_{R}\left(x, y, f_{n}\right)$ is imaged in color scale as frequency increases, the SRSI is obtained as shown in Figure 8(b).

\section{Pyroshock Reconstruction and Verification}

3.1. Reconstruction of Linear Explosive Induced Pyroshock in CFRP Specimen. In this section, pyroshock data in ref [16] was secured to verify and compare the performance of the developed algorithm (Table 1). The pyroshock data were obtained by exploding the linear pyrotechnical device in the quasi-isotropic CFRP sandwich panel. The laser shock was obtained for the same CFRP specimen, and the PWPI and SRSI were obtained using the developed algorithm. The verification of the algorithm was conducted by comparing the real pyroshock with the reconstructed pyroshock. We describe each step of Figure 1 in detail to help understand the reconstruction process.

3.1.1. Linear Explosive Induced Pyroshock Measurement in CFRP Specimen. The pyroshock was generated by exploding a 230-mm linear pyrotechnical device on a CFRP specimen as shown in Figure 9(a). Three LDV sensors were used to measure pyroshock at each measurement point indicated in Figure 9(b). The measured pyroshock was converted into a time domain signal in acceleration as shown in Figure 9(c) through the conversion process and stored in the PC.

3.1.2. Laser Shock Scanning Measurement in CFRP Specimen. The same specimen used in pyroshock measurement was installed as shown in Figure 10(a), and the laser scanning process was performed along the scanning path as shown in Figure 10(b). When the laser scanning process was finished, the laser scanning data of the 4-dimensional shape was obtained as shown in Figure 10(c). To simulate $230 \mathrm{~mm}$ long linear pyrotechnical device, eleven PZT sensors were installed at intervals of $23 \mathrm{~mm}$, as shown in Figure 11(a). The pyrotechnical device used in this paper started to explode from the right and had a principal propagation direction of 19.6 degree [18], so we phase arrayed the laser scanning data and synthesized it as shown in Figure 11(b). The phasedarray laser scanning data were used as $L(x, y, t)$. Figure 11(c) showed the extraction of laser shock data at the same point as the pyroshock measurement point.

3.1.3. Shock Response Spectrum Reconstruction of Linear Explosive Induced Pyroshock. After completion of the laser shock and pyroshock data acquisition, the SRS reconstruction process was performed as described in Section 2.3. We used the measurement points 1 and 2, as shown in Figure 12(a), as the training points to reconstruct the SRS. Measurement point 3 was used as the verification point to verify the reconstruction results. In other words, the real pyroshock signals obtained in the only measurement points 1 and 2 were used to train the algorithm and the algorithm provided the 


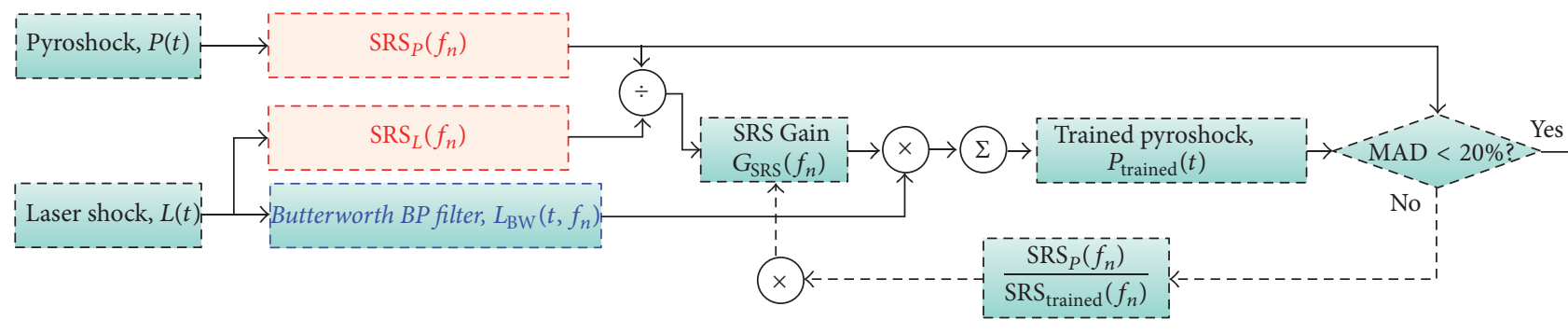

(a)
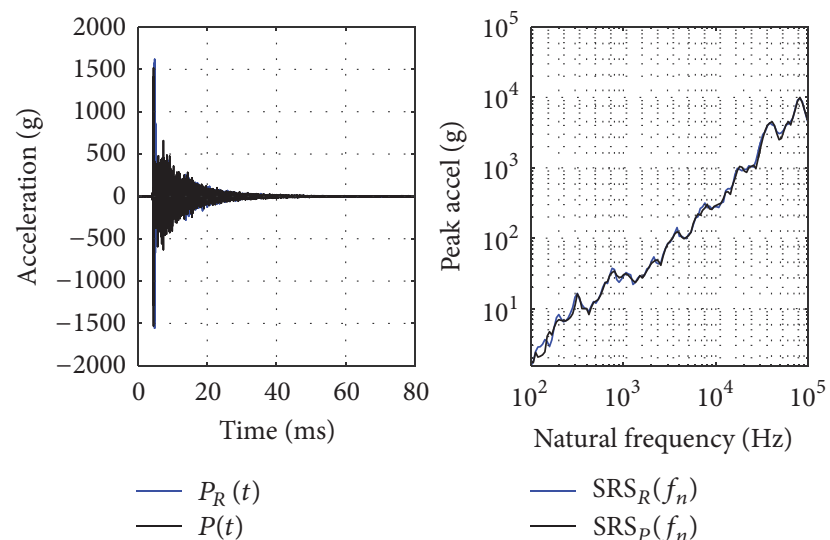

(b)

FIgURE 6: (a) Test algorithm 2. (b) Reconstruction results of the test algorithm 2.

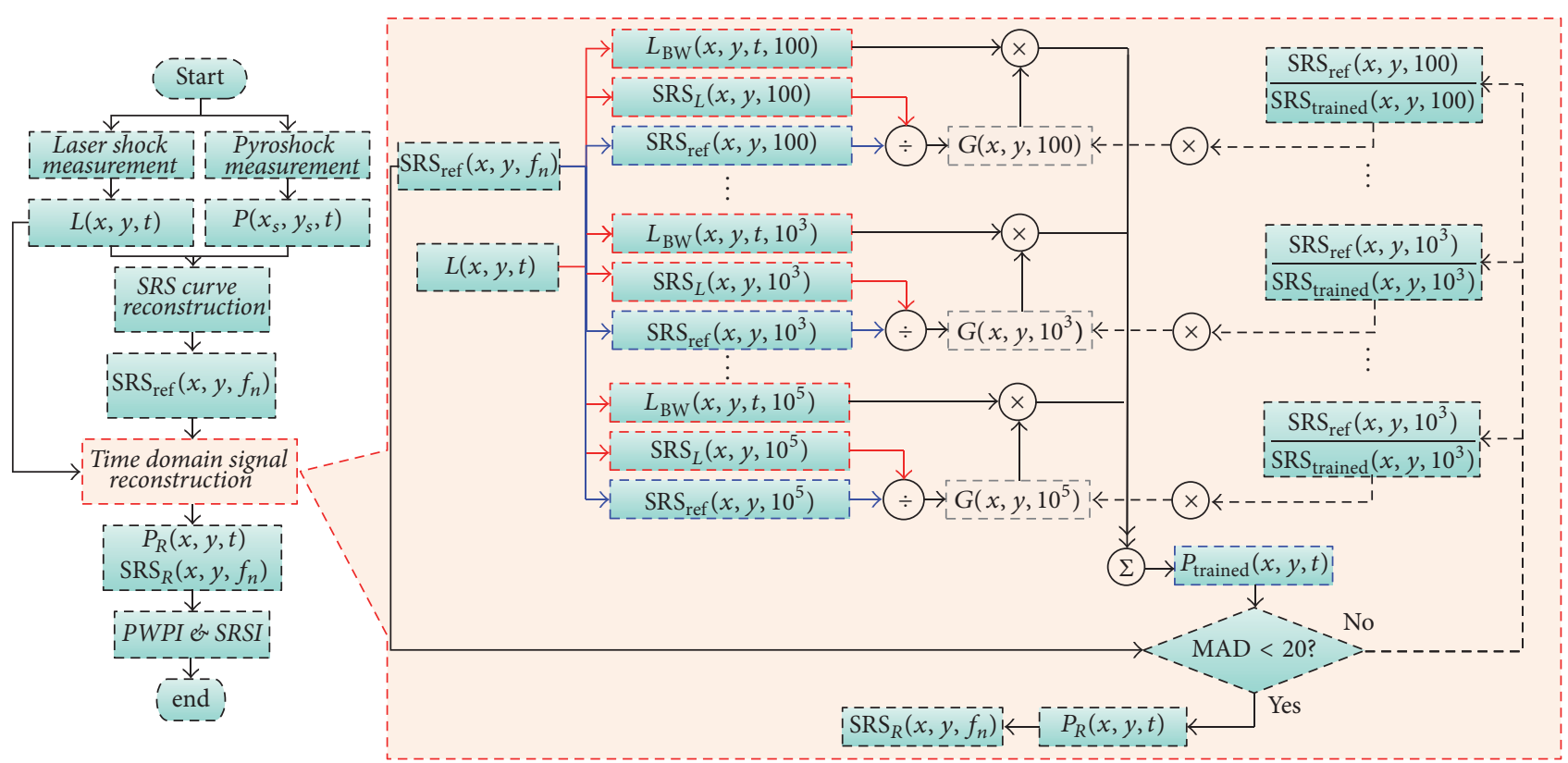

FIGURE 7: Reconstruction algorithm of pyroshock time domain signal. 


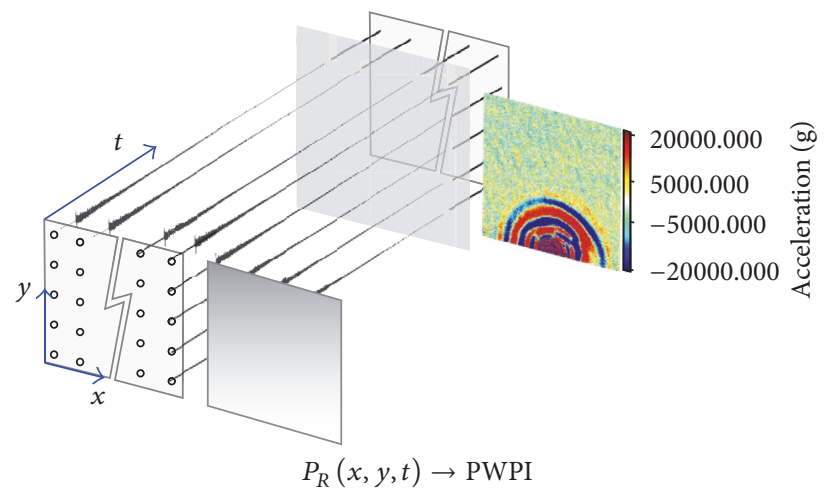

(a)

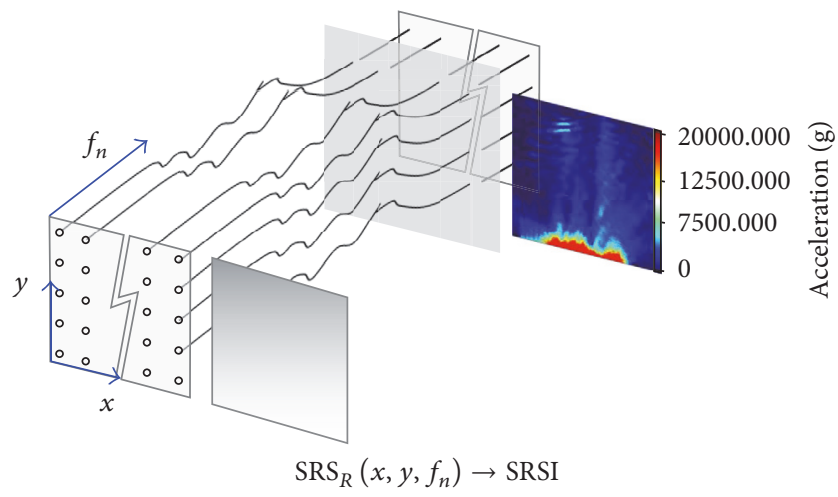

(b)

FIGURE 8: Pyroshock propagation evaluation; (a) PWPI; (b) SRSI.

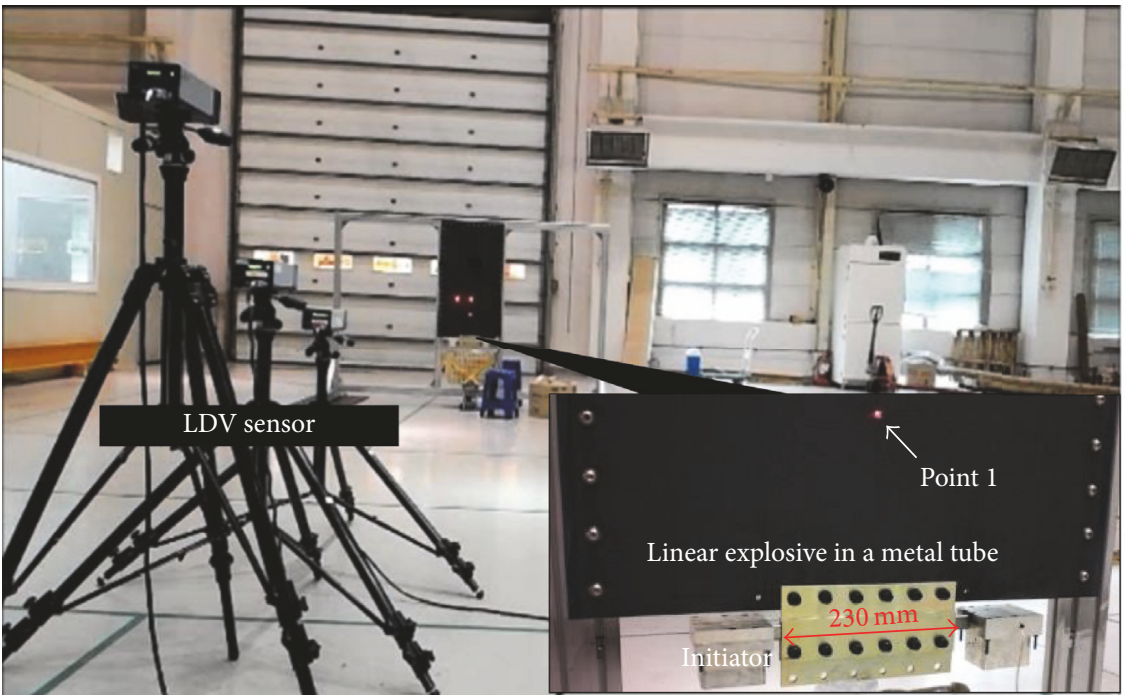

(a)
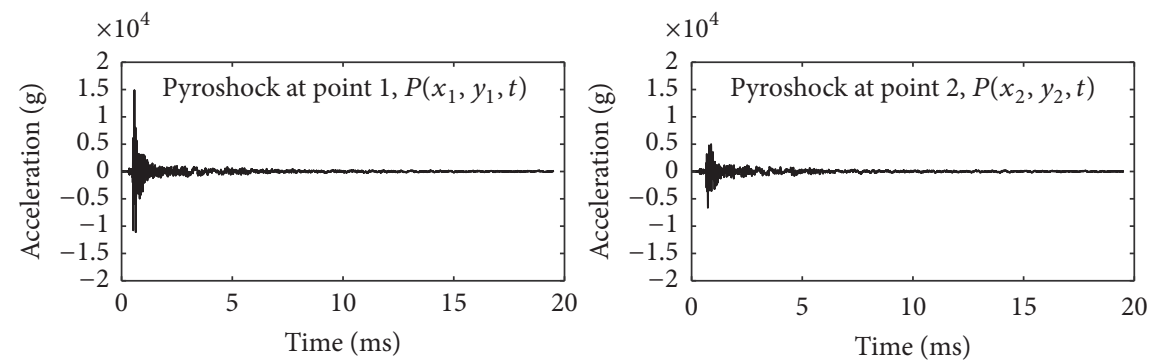

(c)

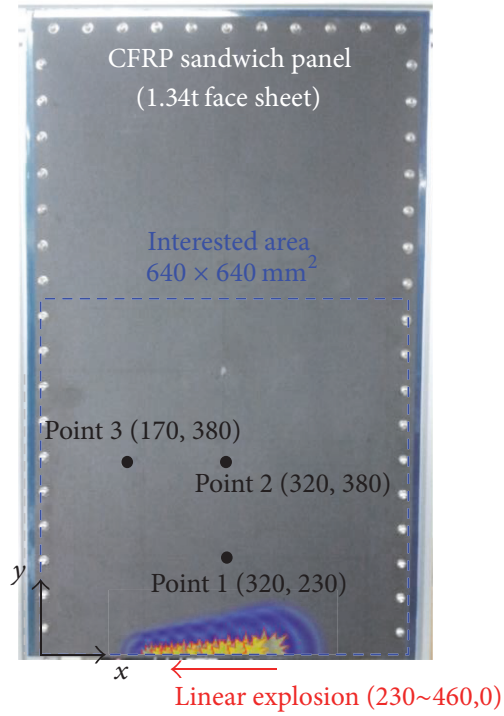

(b)

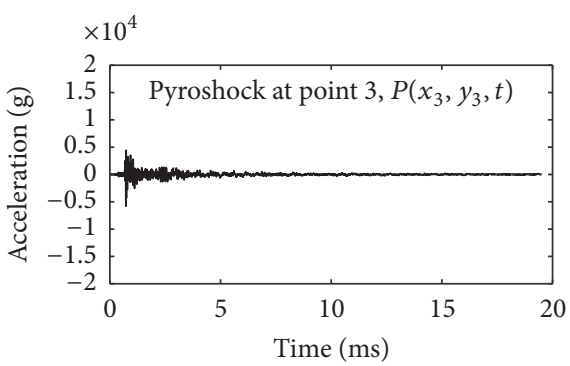

FIGURE 9: Linear explosive induced pyroshock measurement on the CFRP specimen. (a) Experimental setup. (b) Sensing point on the test specimen. (c) Time domain signal of linear explosive induced pyroshock.

TABLE 1: Laser shock measurement condition for reconstruction of linear explosive induced pyroshock.

\begin{tabular}{|c|c|c|c|c|c|}
\hline Shock source & $F s(\mathrm{MHz})$ & Filter $(\mathrm{kHz})$ & Number of samples & PRF $(\mathrm{Hz})$ & Scan area $(\mathrm{mm})$ \\
\hline Laser shock & 1.25 & $0.1 \sim 100$ & 600 & 1,000 & $\begin{array}{c}\text { Width }=640 \\
\text { Height }=640 \\
\text { Interval }=2\end{array}$ \\
\hline
\end{tabular}




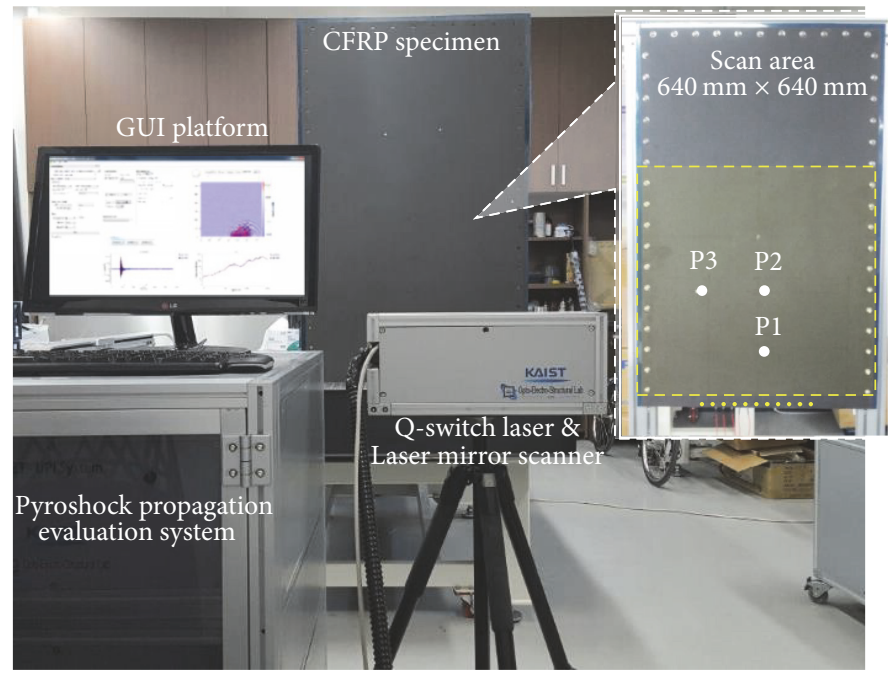

(a)

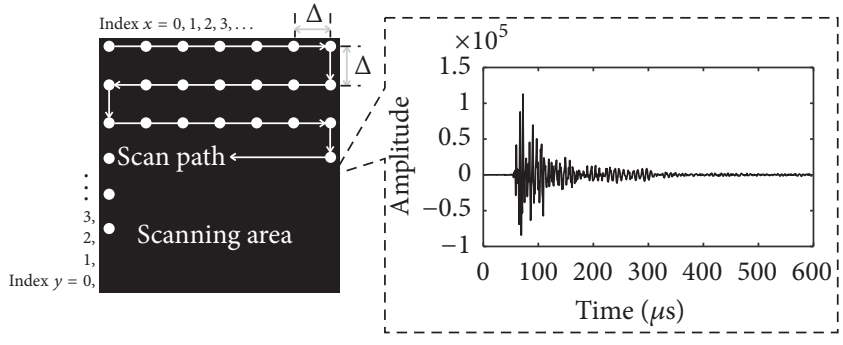

(b)

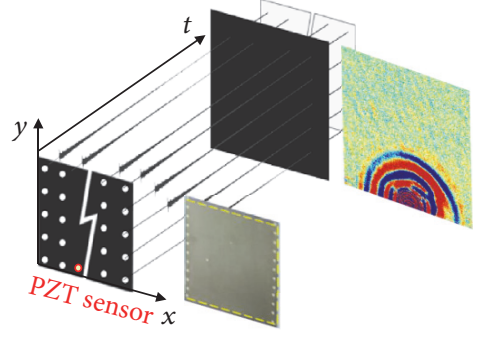

(c)

FIGURE 10: (a) Laser shock measurement setup. (b) Laser scanning process and laser shock time domain signal at an arbitrary point. (c) Four-dimensional laser scanning data structure.

reconstruction results and then the results were compared with the real pyroshock at the measurement point 3 . The reconstruction results at the training points are shown in Figure 12(b). The black signal represents the SRS of the real pyroshock and the blue signal represents the SRS obtained through the reconstruction process. At the point 1, the SRS was trained with a MAD of $4.34 \%$. At the point 2 , the SRS was trained with a MAD of $20.80 \%$.

\subsubsection{Time Domain Signal Reconstruction of Linear Explosive} Induced Pyroshock. The time domain signal of pyroshock was reconstructed by substituting the information from $\operatorname{SRS}_{\text {ref }}\left(x, y, f_{n}\right)$ to $L(x, y, t)$ via the method described in Section 2.4. The reconstruction results of measurement points 1 and 2 used as training points are shown in Figures 13 and 14 . The blue signal represents the reconstruction result and the black signal represents the real pyroshock. At measurement point 1 , the time domain signal was reconstructed with a PAD of $8.96 \%$ and the SRS was reconstructed with a MAD of $22.04 \%$. At the measurement point 2, the time domain signal was reconstructed with a PAD of $19.43 \%$ and the SRS was reconstructed with a MAD of $21.84 \%$. Since we confirmed that the two training points were reconstructed to good similar levels, we obtained $P_{R}(x, y, t)$ and $\operatorname{SRS}_{R}\left(x, y, f_{n}\right)$ by reconstructing pyroshock at all points using $G_{\mathrm{SRS}, \mathrm{O}}\left(f_{n}\right)$ obtained in the training process.

3.1.5. Pyroshock Wave Propagation Image and Shock Response Spectrum Image of Linear Explosive Induced Pyroshock. The obtained $P_{R}(x, y, t)$ was imaged in color scale at each point along the time and PWPI was obtained as shown in Figure 15(a). Figure 15(a) shows a snapshot of the PWPI at $467 \mu$ s. We can confirm propagation characteristics such as propagation path and pyroshock reflection wave via PWPI. Additionally, PWPI allowed us to see how much of each point was affected by shock waves over time. When the amplitude of $\operatorname{SRS}_{R}\left(x, y, f_{n}\right)$ was imaged in color scale as frequency increases, SRSI was obtained. Through the SRSI, we could ascertain how much the structure was affected by the pyroshock for each frequency. For example, in Figure 15(b), we could see how much each point was affected by the pyroshock with $10 \mathrm{kHz}$ frequency components. We expect to be able to use this SRSI to avoid dangerous regions for the electronic components which are sensitive to certain frequency ranges.

3.1.6. Verification of Linear Explosive Induced Pyroshock Reconstruction Result. To verify the obtained PWPI and 


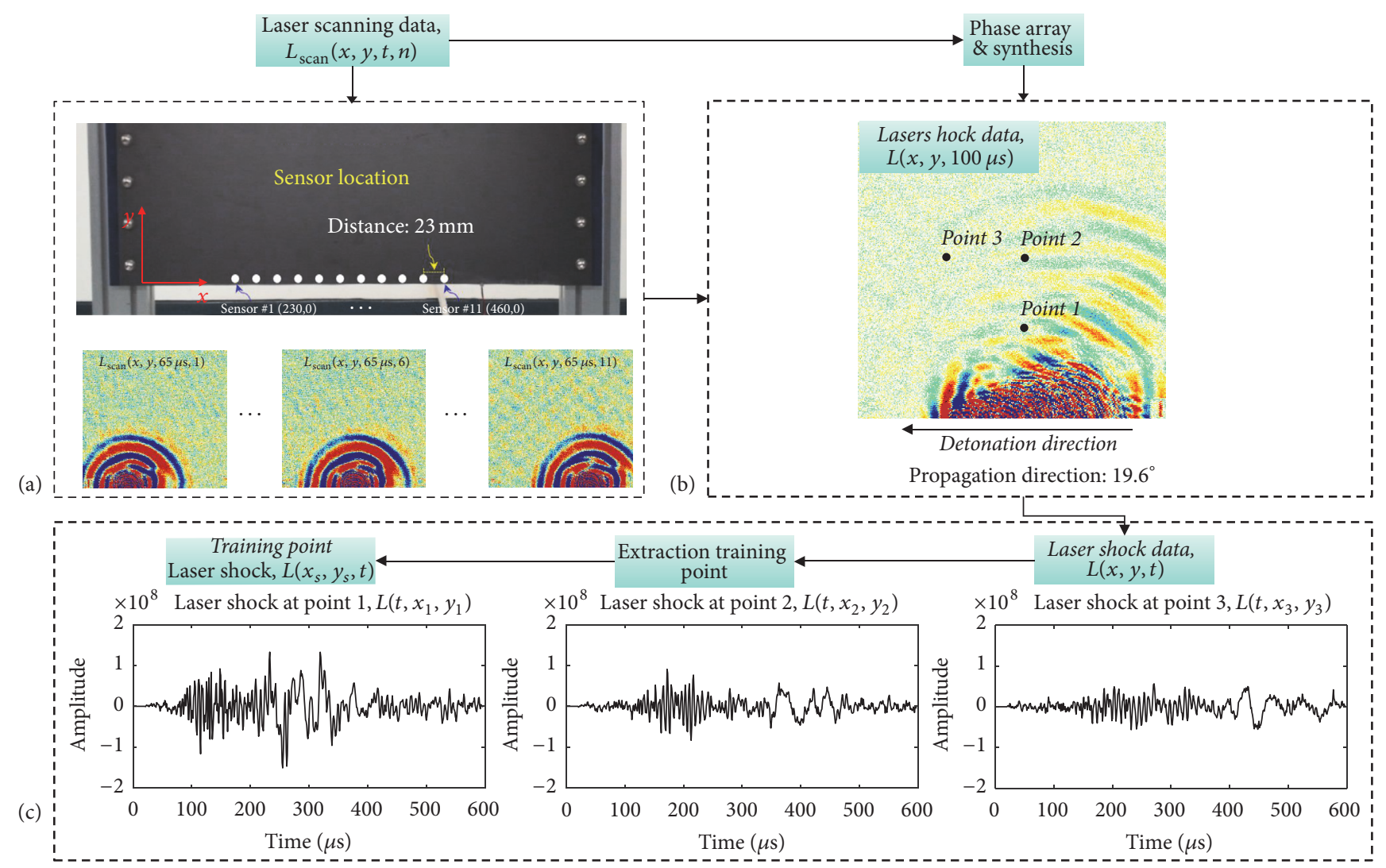

Figure 11: (a) Snapshots of laser scanning data at $65 \mu$ s obtained by each sensor. (b) Snapshot of synthesized laser scanning data at $100 \mu$ s. (c) Training point laser shock, $L\left(x_{s}, y_{s}, t\right)$.

SRSI, we compared the reconstruction result with the real pyroshock at the measurement point 3 set as the verification point. The comparison result is shown in Figure 16. The black signal is the real pyroshock, and the blue signal is the reconstruction result. At the verification point, the time domain signal was reconstructed with a PAD of $19.83 \%$, and the SRS was reconstructed with a MAD of $21.61 \%$. Using these reconstruction results, we could confirm the attenuation characteristics of pyroshock over time and distance. Figure 17(b) could be obtained by plotting $\operatorname{SRS}_{R}\left(x, y, f_{n}\right)$ along the red line shown in Figure 17(a). As shown in Figure 17(b), it could be seen that the SRS attenuates exponentially with distance from the explosion source. Figure 18 could be obtained by plotting $P_{R}(x, y, t)$ along the red line shown in Figure 17(a). As shown in Figure 18, it could be seen that the time domain signal attenuates exponentially with time and distance from the explosion source.

Reconstruction using measurement points 1 and 2 as training points and measurement point 3 as verification point confirmed that pyroshock was reconstructed with averaged PAD of $16.07 \%$ and MAD of $21.83 \%$. To verify more closely the developed algorithm, this process was repeatedly conducted by changing the training and verification points. Figure 19 shows the results of reconstruction using measurement points 1 and 3 as training points and measurement point 2 as verification point. Figure 20 shows the results of reconstruction using measurement points 2 and 3 as training points and measurement point 1 as verification points. All three verifications were reconstructed at similar levels in PAD and MAD.

\subsection{Reconstruction of Point Explosive Induced Pyroshock in Disk Type Specimen}

3.2.1. Point Explosive-Induced Pyroshock Measurement in Disk Type Specimen. In this section, we analyzed the propagation of the point explosive induced pyroshock in specimens of steel 4340 material. The specimen had a thickness of $27 \mathrm{~mm}$ and a diameter of $300 \mathrm{~mm}$. The pyroshock measurement setup is shown in Figure 21. Pyroshock was induced by a 1/2inch explosive bolt as shown in Figure 21 and measured by three LDVs. The pyroshock was measured at $10 \mathrm{~mm}, 50 \mathrm{~mm}$, and $90 \mathrm{~mm}$ from the explosion source, and detailed DAQ conditions are shown in Table 2.

3.2.2. Laser Shock Measurement in Disk Type Specimen. Laser shock data were obtained for the same specimen used in pyroshock measurement. The laser shock generated by Qswitch laser was collected by a PZT sensor. The scanning area was set to include pyroshock measurement points as shown in Figure 22. Detailed DAQ conditions are shown in Table 3.

3.2.3. Reconstruction of Pyroshock in Disk Type Specimen. The pyroshock reconstruction process was performed using 


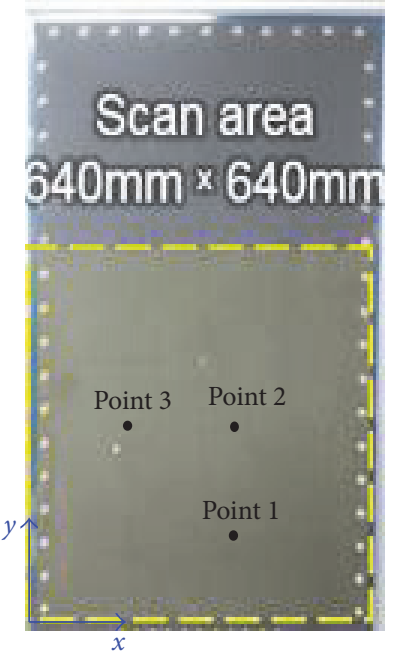

(a)
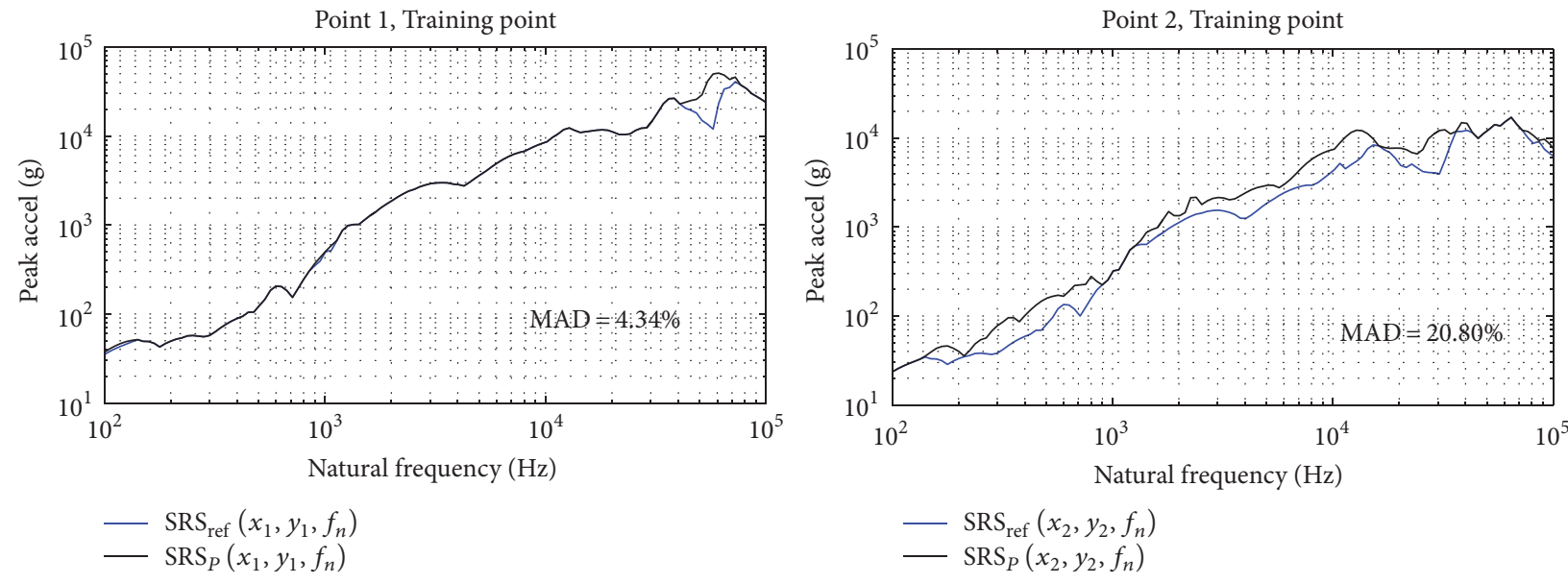

(b)

FIGURE 12: SRS reconstruction on the training points. (a) CFRP specimen. (b) Reconstruction results.
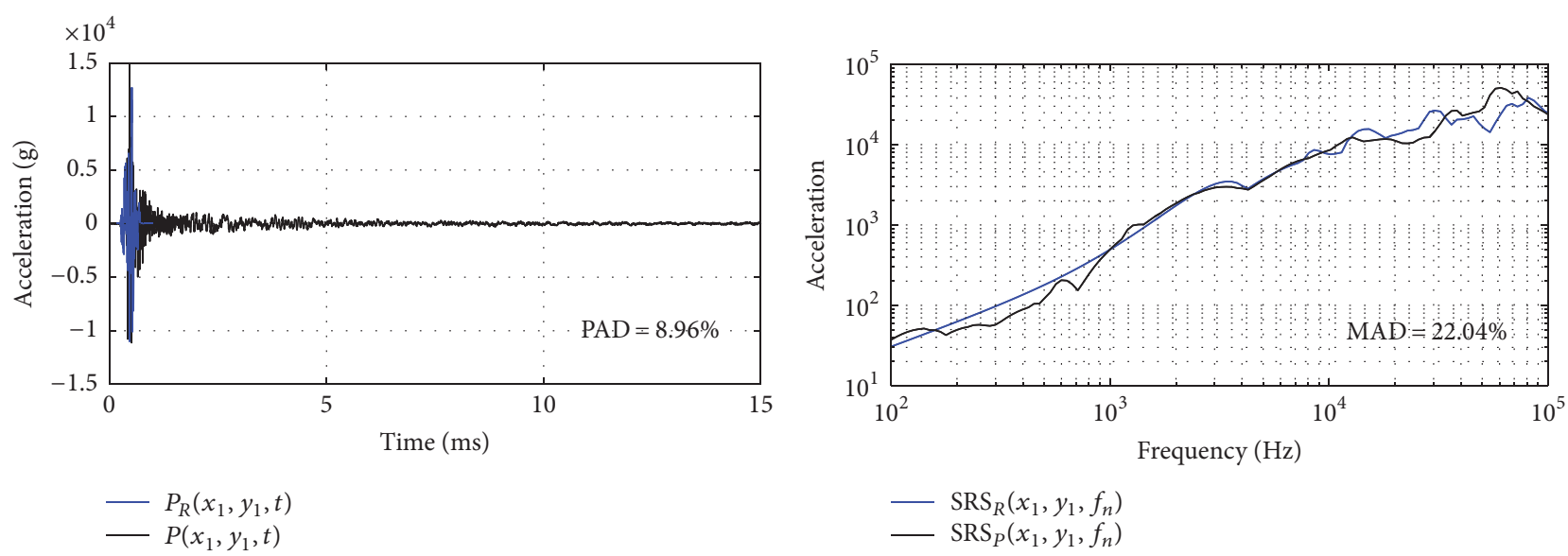

FIGURE 13: Time domain signal reconstruction at point 1, training point. 


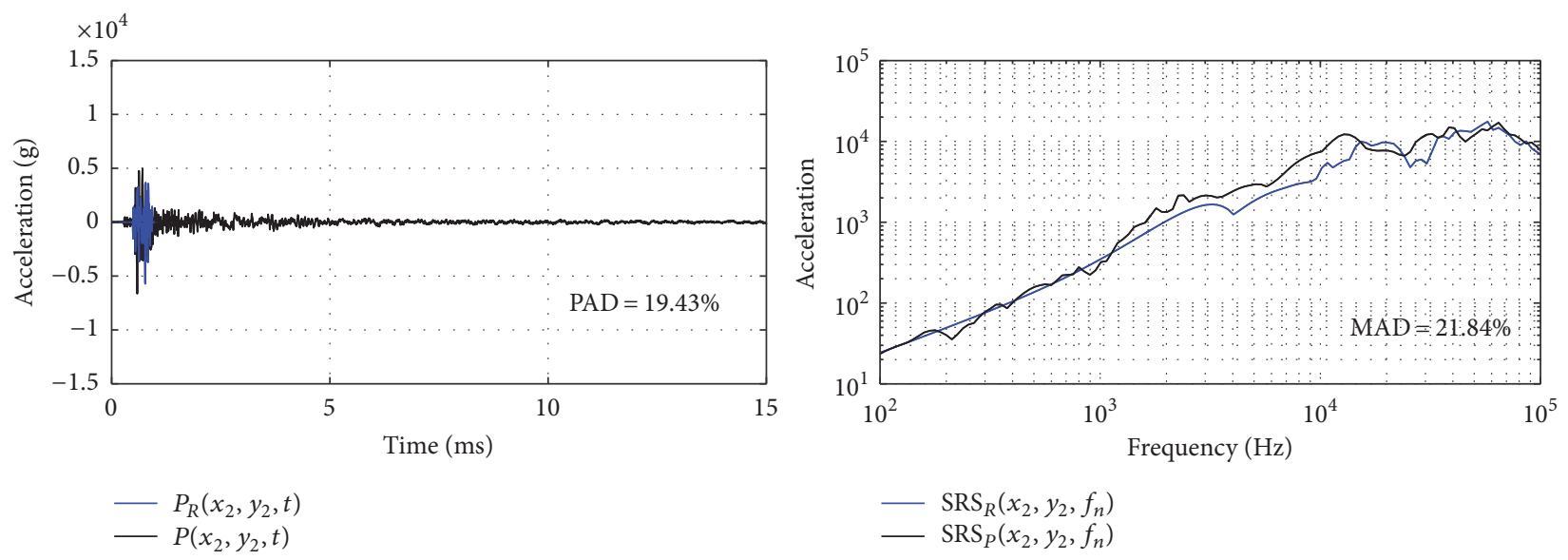

FIGURE 14: Time domain signal reconstruction at point 2, training point.

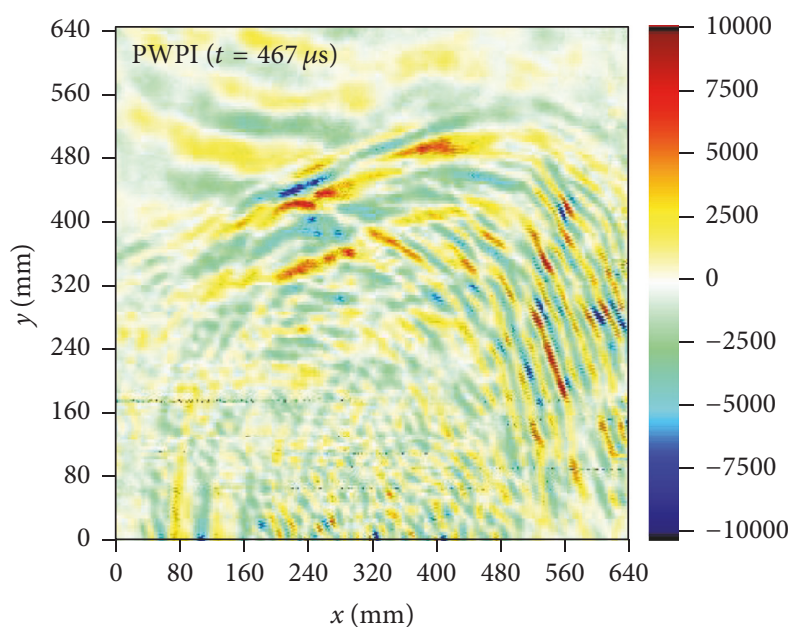

(a)

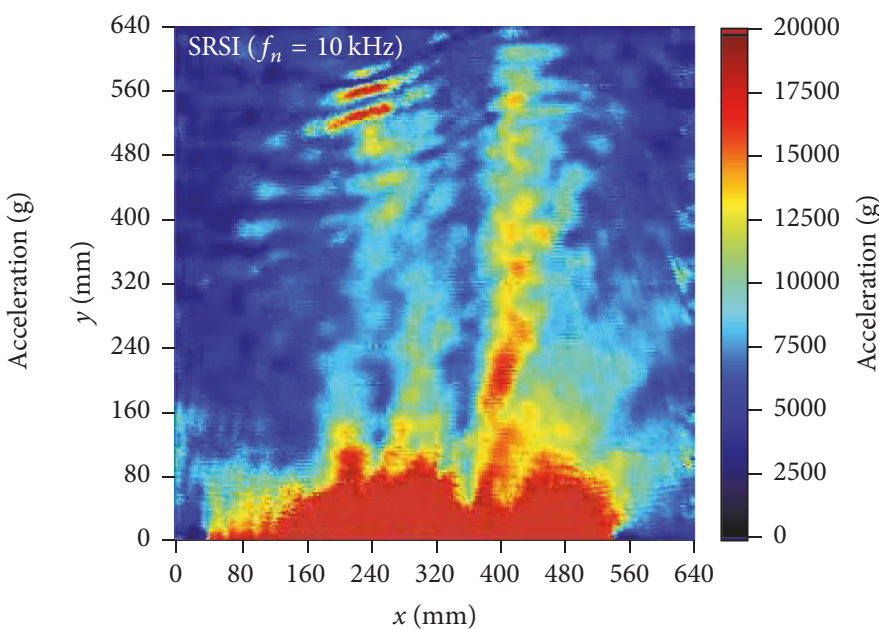

(b)

FIGURE 15: Linear explosive induced pyroshock propagation evaluation; (a) PWPI at $467 \mu$ s; (b) SRSI at $10 \mathrm{kHz}$.
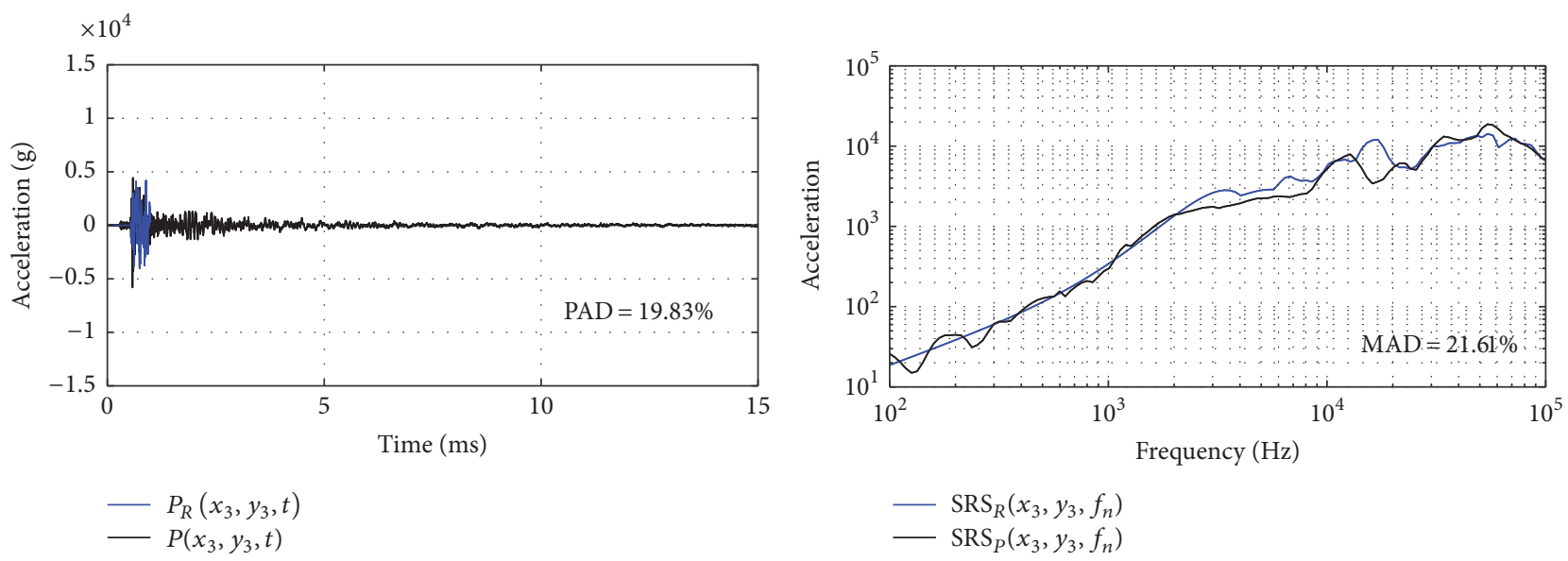

Figure 16: Time domain signal reconstruction at point 3, verification point. 


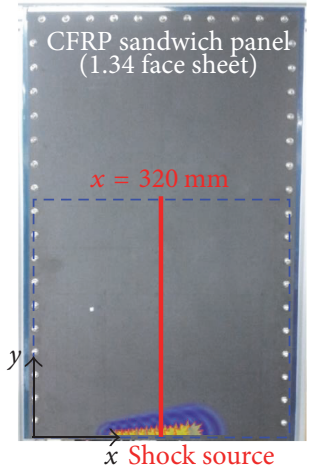

(a)

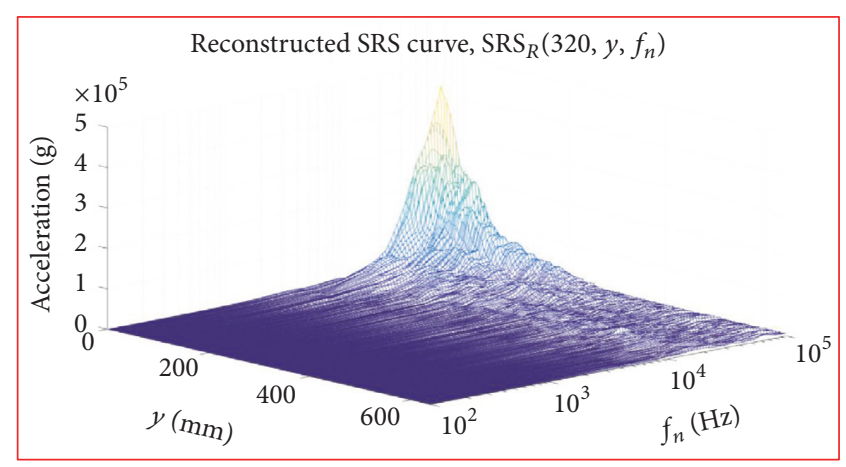

(b)

FIGURE 17: (a) CFRP specimen with red line. (b) Reconstructed SRS along the red line.

TABLE 2: Measurement condition of point explosive induced pyroshock on the disk type specimen.

\begin{tabular}{|c|c|c|c|c|c|c|}
\hline Shock source & $\mathrm{CF}$ & $F s(\mathrm{MHz})$ & Filter (kHz) & Number of samples & $\mathrm{CF}_{\mathrm{mr}}(\mathrm{mm} / \mathrm{s} / \mathrm{V})$ & $A_{\mathrm{dB}}(\mathrm{dB})$ \\
\hline Pyroshock & $\begin{array}{l}\mathrm{CF}_{1}=1.42 \\
\mathrm{CF}_{2}=1.42 \\
\mathrm{CF}_{3}=1.42\end{array}$ & 1 & $0.1 \sim 100$ & 30,000 & 1,000 & $\begin{aligned} A_{\mathrm{dB} 1} & =9 \\
A_{\mathrm{dB} 2} & =6 \\
A_{\mathrm{dB} 3} & =6\end{aligned}$ \\
\hline
\end{tabular}

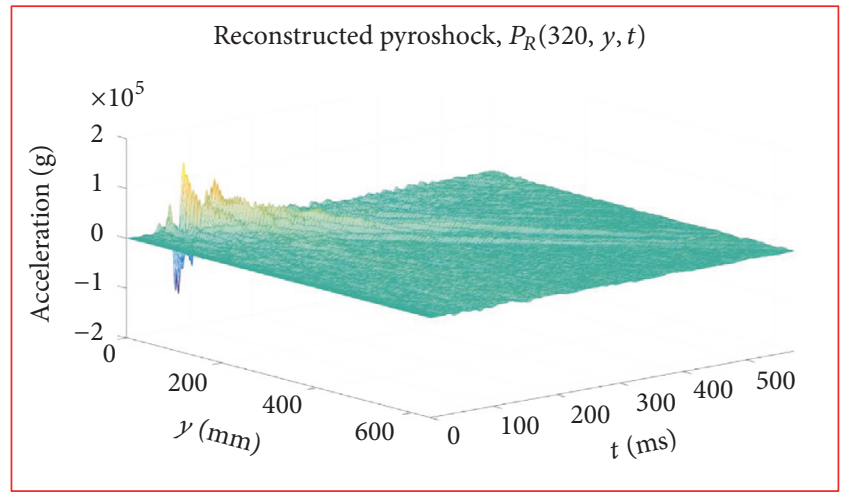

FIGURE 18: Reconstructed time domain signal along the red line.

two arbitrary points of the acquired signals, measurement point 2 and point 3 as the training points. The reconstruction results at the training points are shown in Figure 23. The blue signal represents the reconstruction result and the black signal represents the real pyroshock signal. The reconstruction results showed that the time domain signal at the measurement point 2 was reconstructed with the PAD of $4.88 \%$ and the SRS was reconstructed with the MAD of $29.50 \%$. At measurement point 3 , the time domain signal was reconstructed with the PAD of $1.62 \%$ and the SRS was reconstructed at a similar level of MAD 26.57\%. Figure 24 shows PWPI and SRSI. Figure 24(a) shows a snapshot of PWPI at $60 \mu \mathrm{s}$, and Figure 24(b) shows a snapshot of SRSI at $40 \mathrm{kHz}$.

To verify the algorithm, we compared the reconstruction result and the real pyroshock at the measurement point 1 set as the verification point as shown in Figure 25. Because of comparison at the verification point, the time domain signal was reconstructed with the PAD of $20.59 \%$ and the SRS was reconstructed with the MAD of $30.11 \%$.

3.3. Comparison of Developed Algorithm and Previous Algorithms. Reconstruction of pyroshock using laser shock was first attempted in [18]. In [18], SRS reconstruction results have not been accurate because they tried to compensate for the difference in characteristics between pyroshock and laser shock by simply matching the peak to peak acceleration in the time domain. In $[19,20]$, these researchers have developed an algorithm to compensate for the difference in characteristics of laser shock and pyroshock by statistically predicting the amplitude of pyroshock with distance from the explosion source. They have achieved accurate results by reconstructing point explosive-induced pyroshock on an aluminum plate. However, since the pyroshock is affected not only by the distance from the explosion source but also by the geometry of the structure, the algorithm proposed by $[19,20]$ did not have any mechanism needed to predict pyroshock in complex structures. Figure 26 shows the reconstruction results of the algorithm developed in this paper compared with the previously developed algorithm in [18-20]. Figure 26 shows the reconstruction results of the point explosive induced pyroshock in disk type specimen through each system. Reconstruction was performed using only point 2 and point 3 in Figure 22; point 1 was used as a verification point to verify the algorithm, and Figure 26 shows the reconstruction results at verification point. In each result, the black signal represents the real pyroshock, the blue signal represents the reconstruction result, and the red signal represents the laser shock before gaining. Figure 26(a) shows the reconstruction result using the algorithm presented in [18]. From the results of the SRS reconstruction, only the peak 

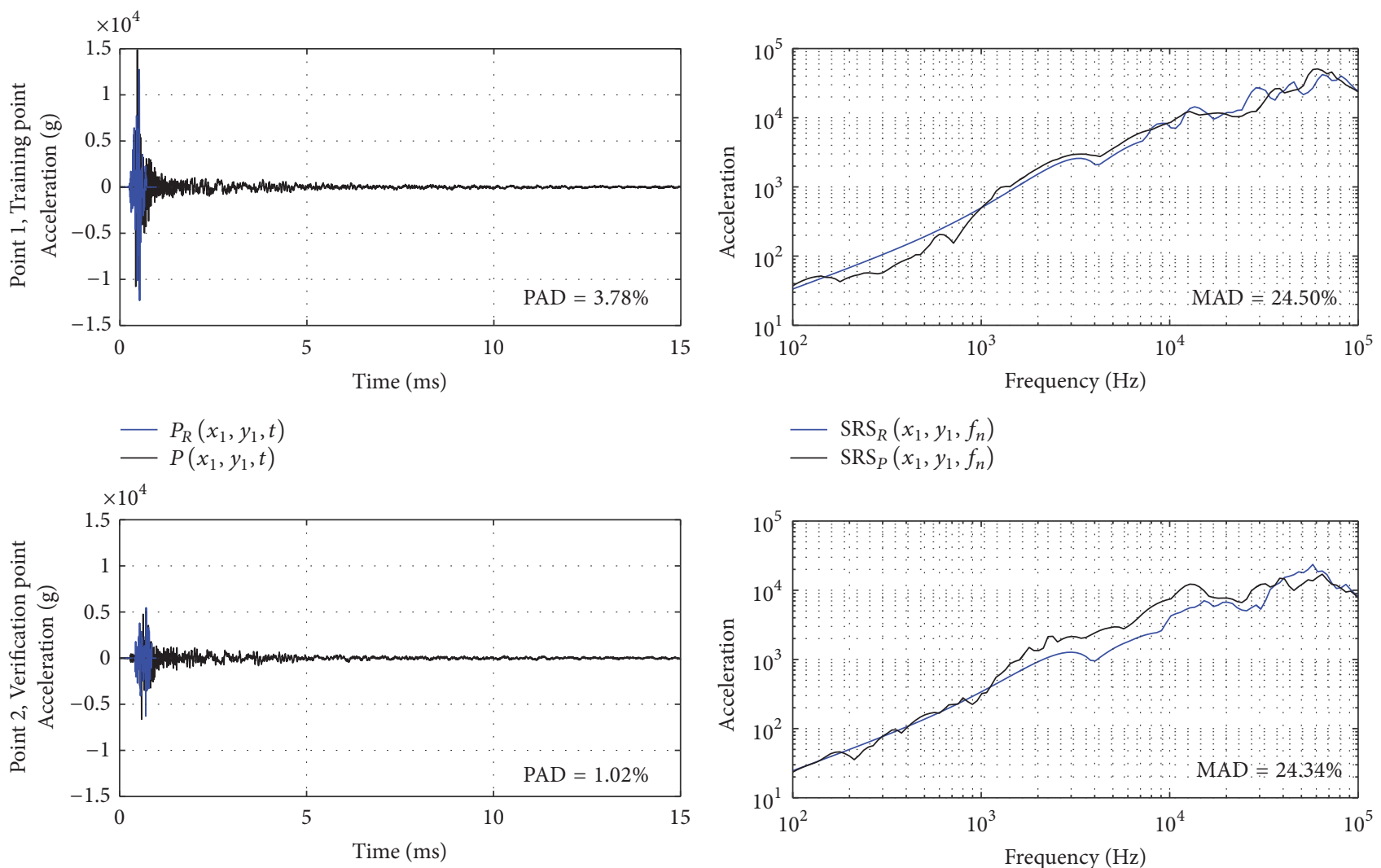

$-\operatorname{SRS}_{R}\left(x_{1}, y_{1}, f_{n}\right)$
$-\operatorname{SRS}_{P}\left(x_{1}, y_{1}, f_{n}\right)$

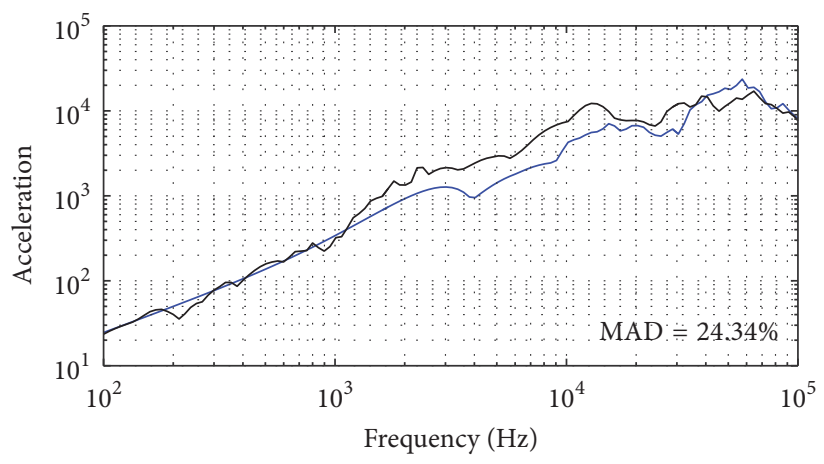

$-P_{R}\left(x_{2}, y_{2}, t\right)$

- $P\left(x_{2}, y_{2}, t\right)$

$-\operatorname{SRS}_{R}\left(x_{2}, y_{2}, f_{n}\right)$

$-\operatorname{SRS}_{P}\left(x_{2}, y_{2}, f_{n}\right)$
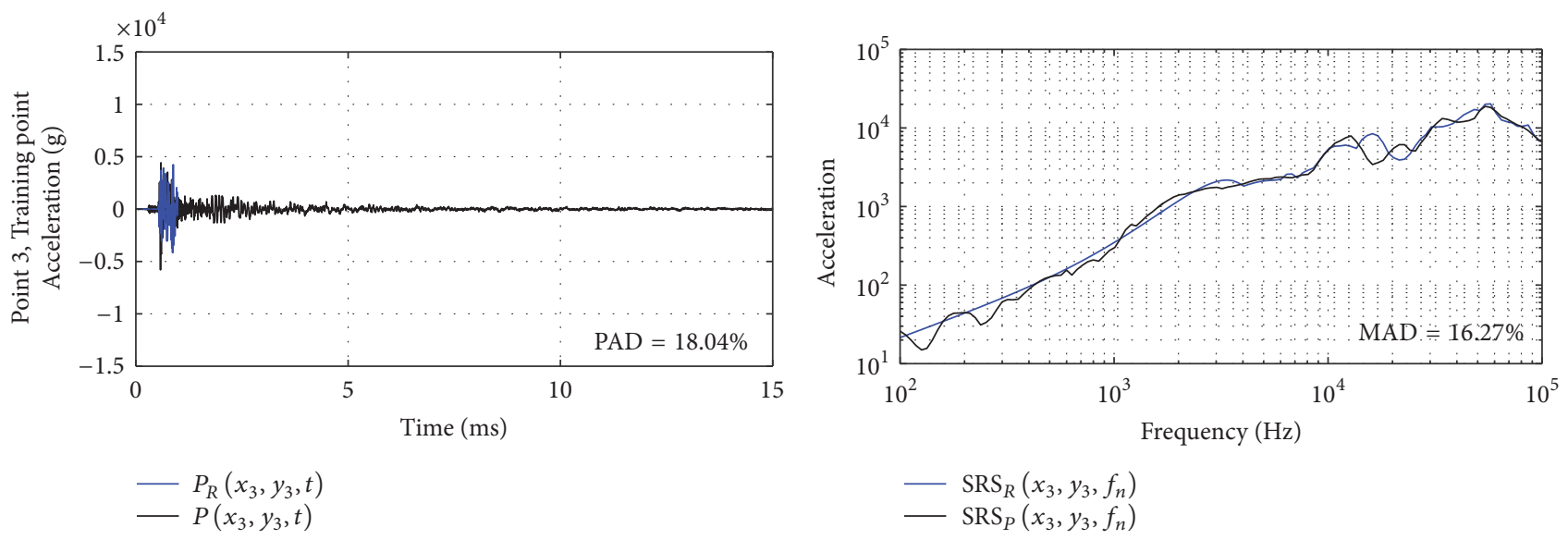

FIGURE 19: Time domain signal reconstruction result in using point 2 as a verification point.

TABLE 3: Measurement condition of laser shock for reconstruction of pyroshock on the disk type specimen.

\begin{tabular}{lccccc}
\hline Shock source & $F s(\mathrm{MHz})$ & Filter $(\mathrm{kHz})$ & Number of samples & PRF $(\mathrm{Hz})$ & Scan area $(\mathrm{mm})$ \\
\hline Laser shock & 1 & $0.1 \sim 100$ & 512 & 50 & Width $=136$ \\
& & & $\begin{array}{c}\text { Height }=104 \\
\text { Interval }=1\end{array}$ \\
\hline
\end{tabular}



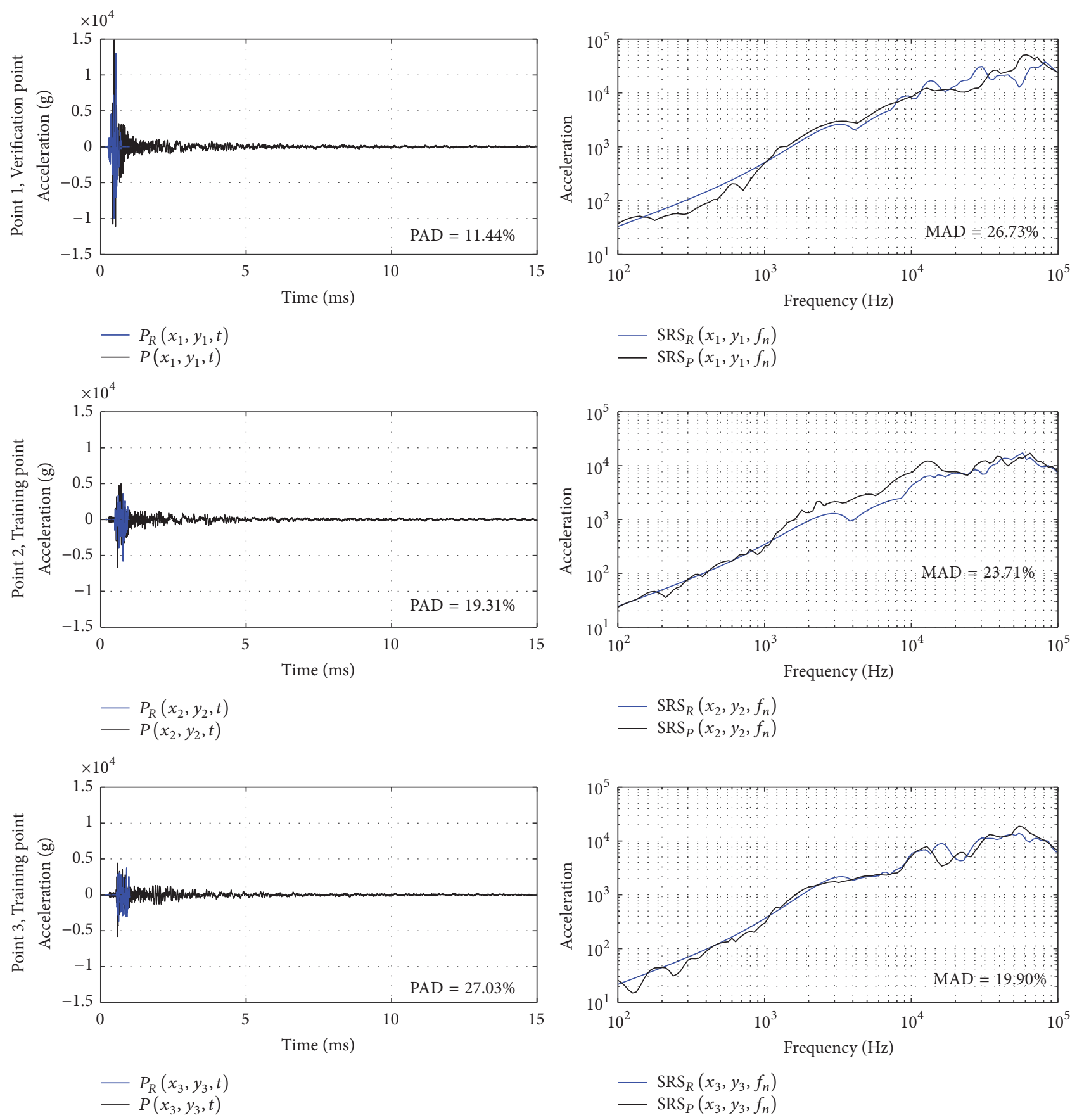

FIgURE 20: Time domain signal reconstruction result in using point 1 as a verification point.

value was adjusted, and the SRS shape was maintained as it is. This indicates that the reconstruction result will be not good if the SRS shape of laser shock differs from the SRS shape of pyroshock. On the other hand, in the case of the algorithm presented in this paper, since the characteristic difference is corrected for each frequency range, the reconstruction result was excellent even though the SRS shape of laser shock differs from the SRS shape of pyroshock as shown in Figure 26(c). Figure 26(b) shows the reconstruction result using the algorithm presented in $[19,20]$. We can see that the reconstruction results were not good because of the problem where the algorithm proposed in $[19,20]$ assumes that the amplitude of the pyroshock is only dependent on the distance from the explosion source. However, the pyroshock not only was dependent on the distance from the explosion source but also depends on the geometry of the structure. Thus, the algorithm presented in $[19,20]$ cannot be successfully used for complex and local structures which do not allow a propagation modelling based exponential attenuation. On the other hand, in the case of the algorithm presented in this paper, it can be confirmed that various types of pyroshock were excellently reconstructed as shown in Table 4. 

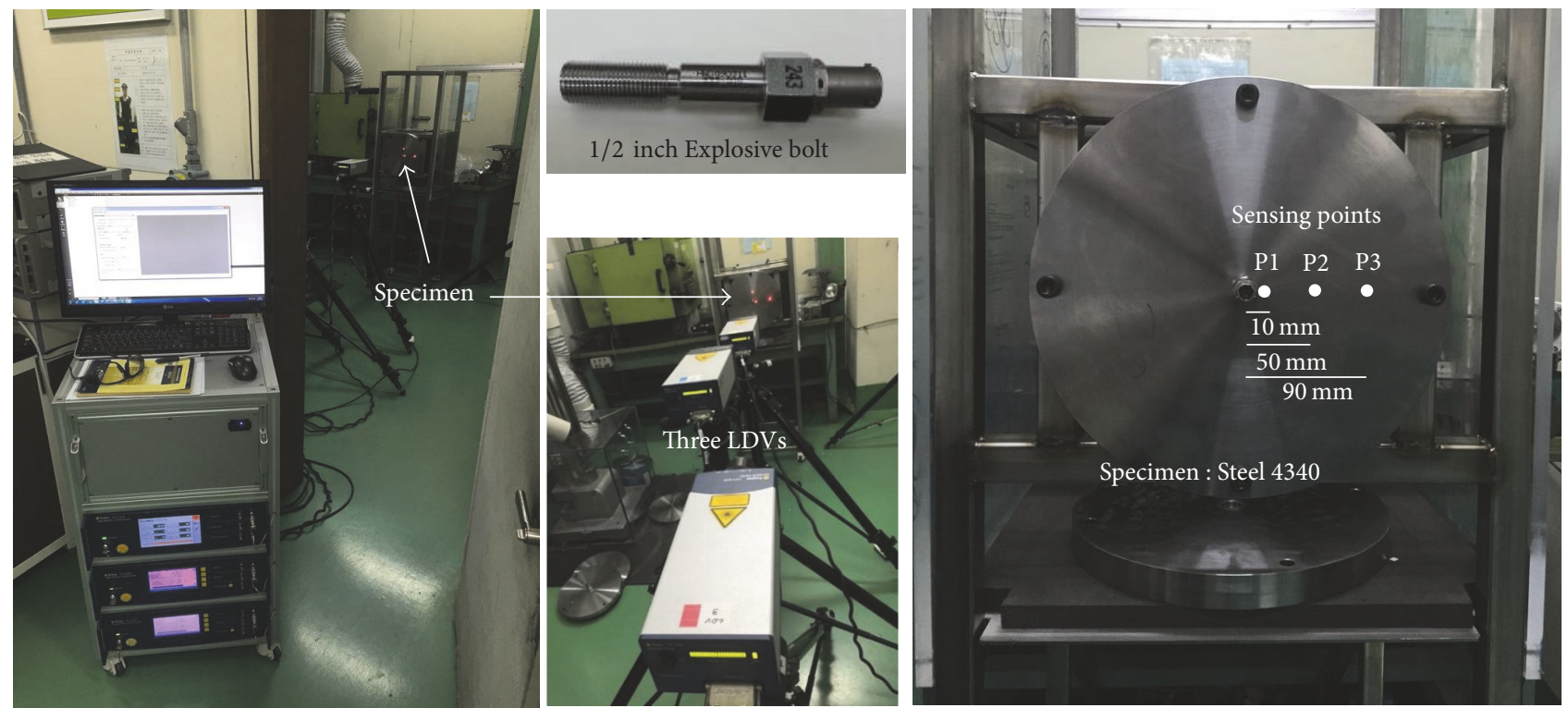

FIGURE 21: Measurement system of point explosive-induced pyroshock and the disk type specimen.

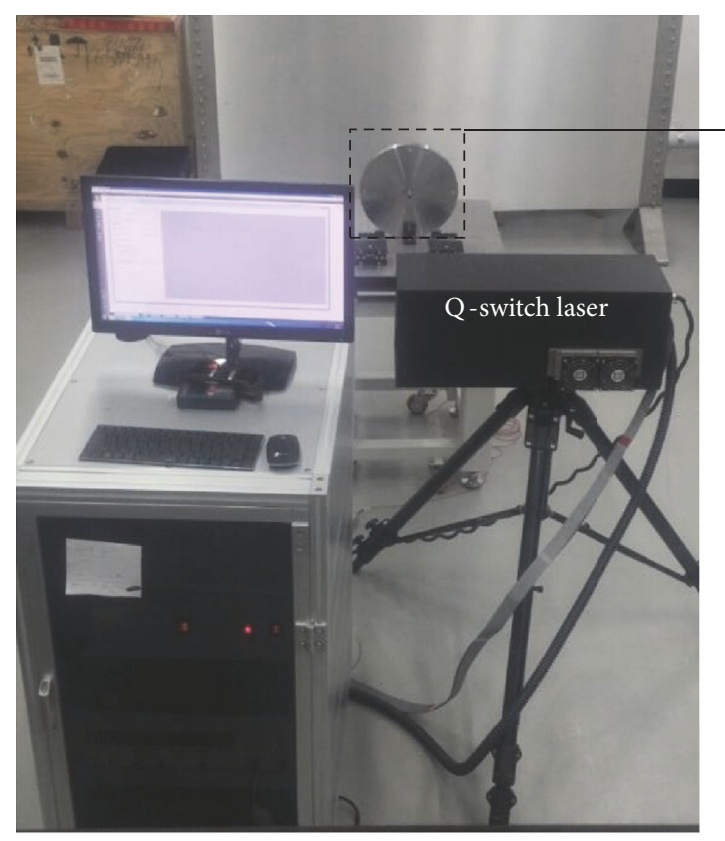

(a)

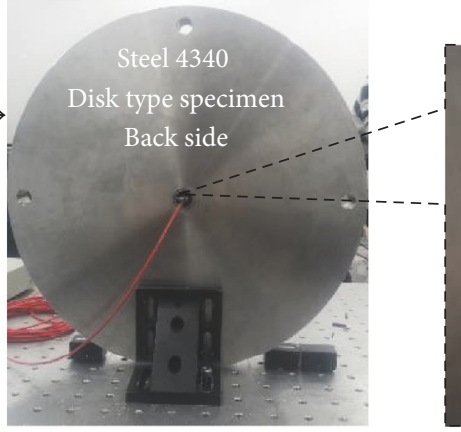

(b)

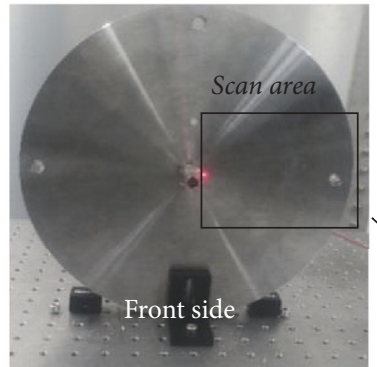

(d)

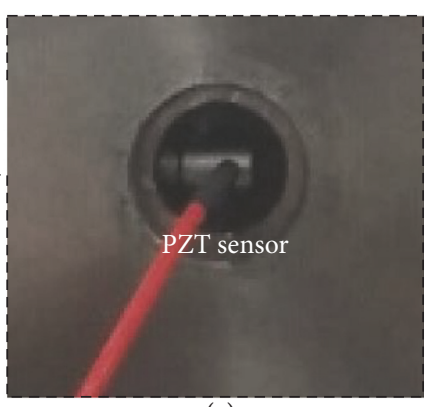

(c)

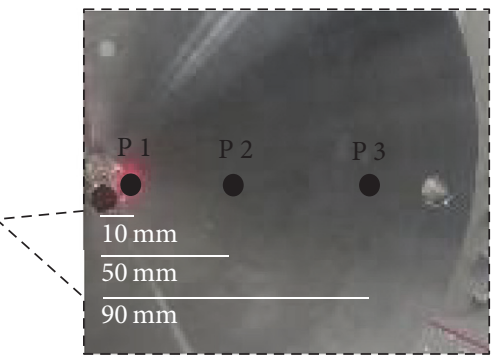

(e)

FIGURE 22: Scanning measurement system of laser shock for reconstruction of explosive induced pyroshock on the disk type specimen.

\section{Conclusions}

In this paper, we developed a pyroshock reconstruction algorithm using laser shock. The developed system used a laser scanning technique to acquire laser shock and reconstructed it with pyroshock using iterative signal decomposition and synthesis method. This algorithm obtained the gain to compensate the difference in characteristics between laser shock and pyroshock based on SRS. The gain was applied to laser shock signal decomposed by Butterworth filter in each frequency band. The stopband effect in band decomposition was compensated by iteration to improve the reconstruction result. We reconstructed linear explosive induced pyroshock using the developed algorithm as well as point explosive. PWPI and SRSI were obtained through the reconstruction. We could confirm propagation characteristics such as propagation path and reflection wave of pyroshock through PWPI. Through the SRSI, we could ascertain how much the structure was affected by the pyroshock for each frequency. To verify the algorithm, we compared the reconstruction result with 

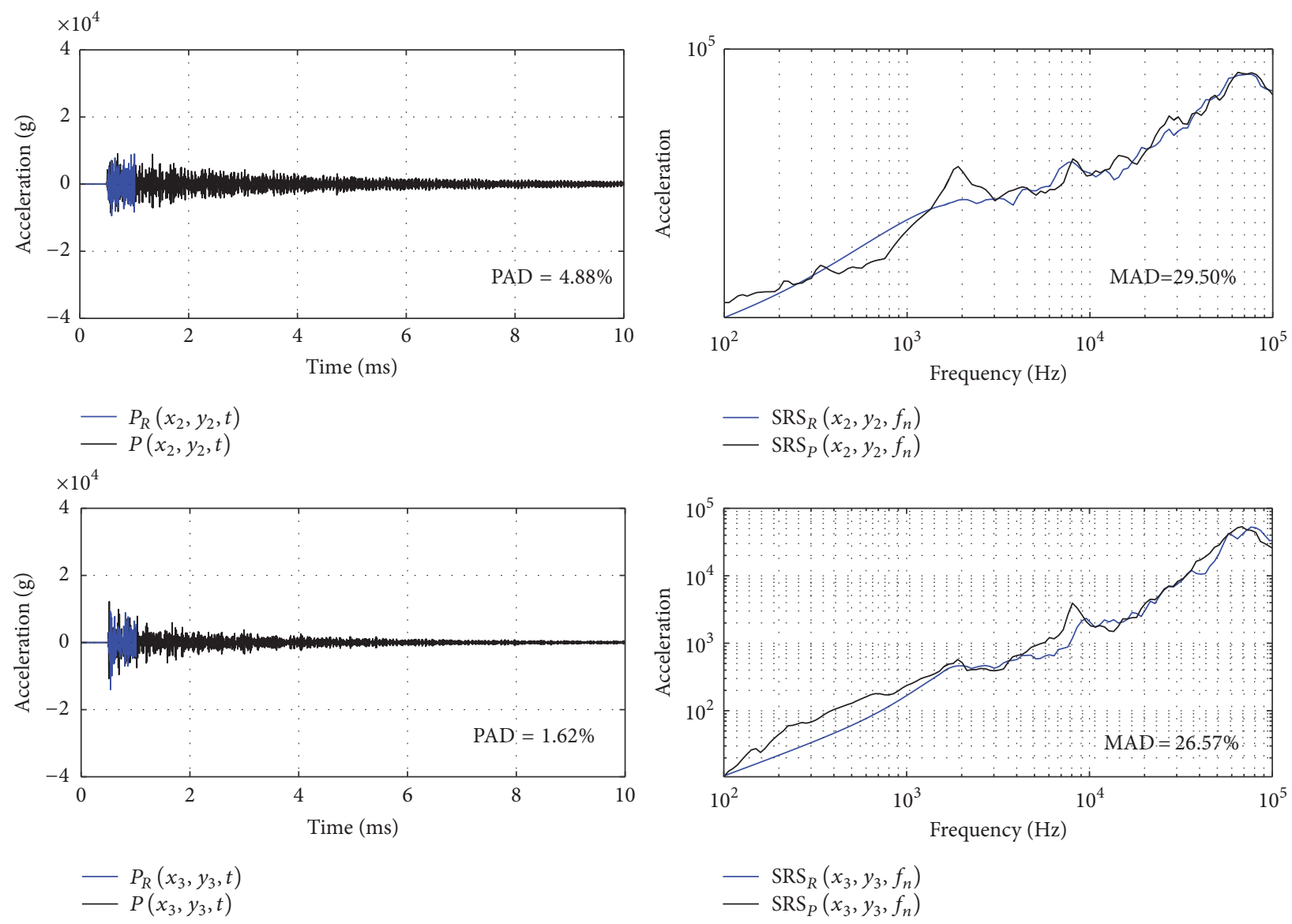

$-P_{R}\left(x_{3}, y_{3}, t\right)$

$-\operatorname{SRS}_{P}\left(x_{3}, y_{3}, f_{n}\right)$

FIGURE 23: Reconstruction results of pyroshock on the disk type specimen at the training points.

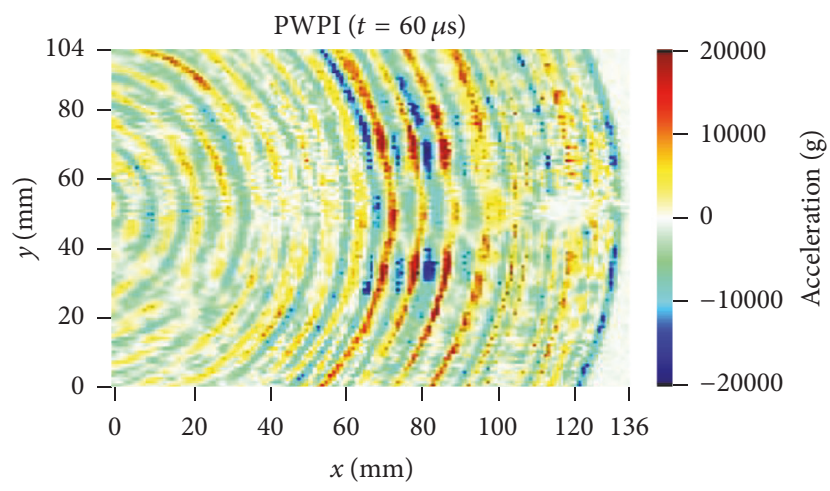

(a)

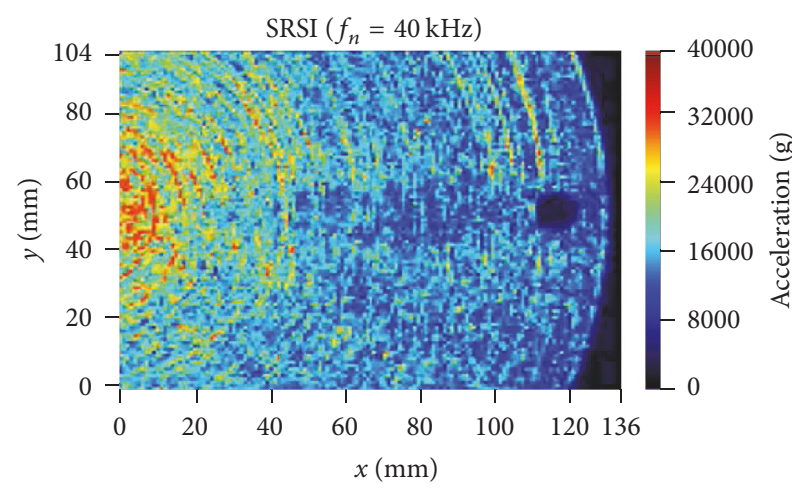

(b)

FIGURE 24: Pyroshock propagation evaluation on the disk type specimen; (a) PWPI at $60 \mu \mathrm{s}$. (b) SRSI at $40 \mathrm{kHz}$.

TABLE 4: Reconstruction results and comparison of the proposed algorithm and previous algorithms.

$$
\text { Developed algorithm }
$$$$
\text { Ref [18] }
$$

$\operatorname{Ref}[19,20]$

Training point Verification point Training point Verification point Training point Verification point MAD (\%) PAD (\%) MAD (\%) PAD (\%) MAD (\%) PAD (\%) MAD (\%) PAD (\%) MAD (\%) PAD (\%) MAD (\%) PAD (\%)

\begin{tabular}{|c|c|c|c|c|c|c|c|c|c|c|c|c|}
\hline CFRP-linear & 21.94 & 14.02 & 21.61 & 19.83 & 31.87 & 20.55 & 34.51 & 19.10 & \multicolumn{4}{|c|}{ Could not be reconstructed } \\
\hline Disk-point & 28.04 & 3.25 & 30.11 & 20.59 & 45.65 & 7.30 & 52.64 & 18.03 & 36.40 & 45.30 & 63.22 & 48.33 \\
\hline Average & 24.99 & 8.64 & 25.86 & 20.21 & 38.76 & 13.93 & 43.58 & 18.57 & 36.4 & 45.3 & 63.22 & 48.33 \\
\hline
\end{tabular}



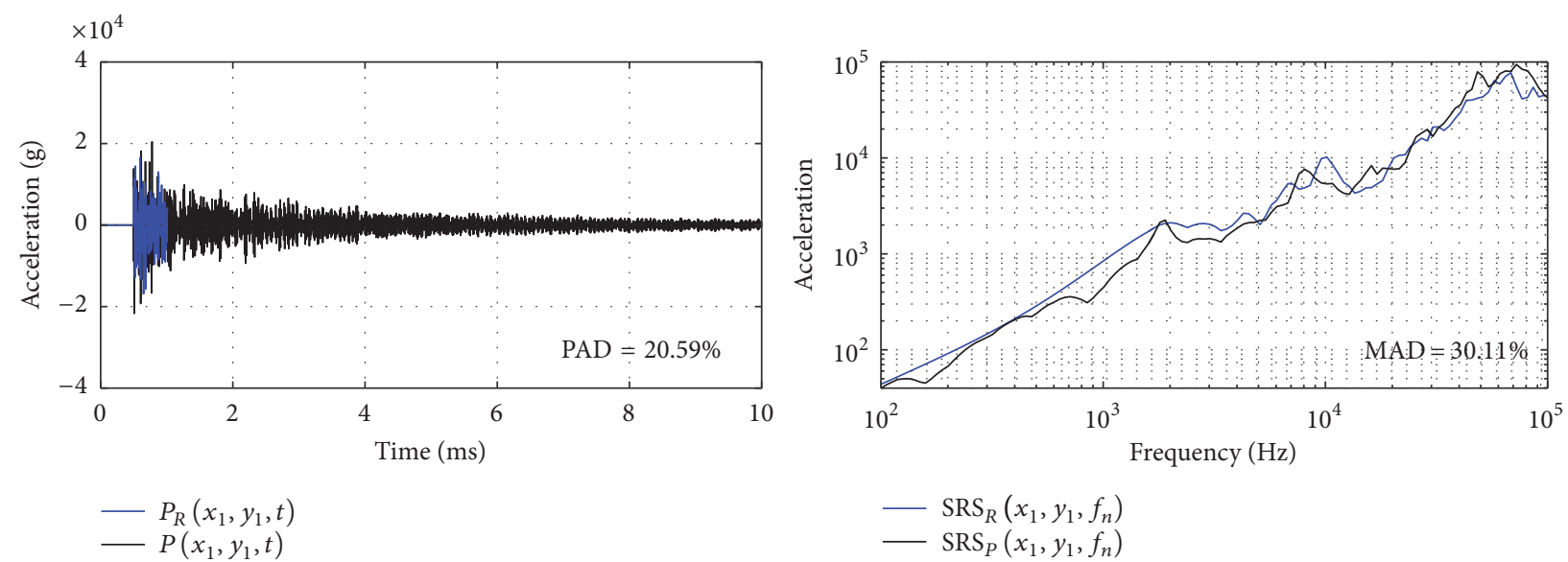

FIGURE 25: Reconstruction results of pyroshock on the disk type specimen at the verification point.
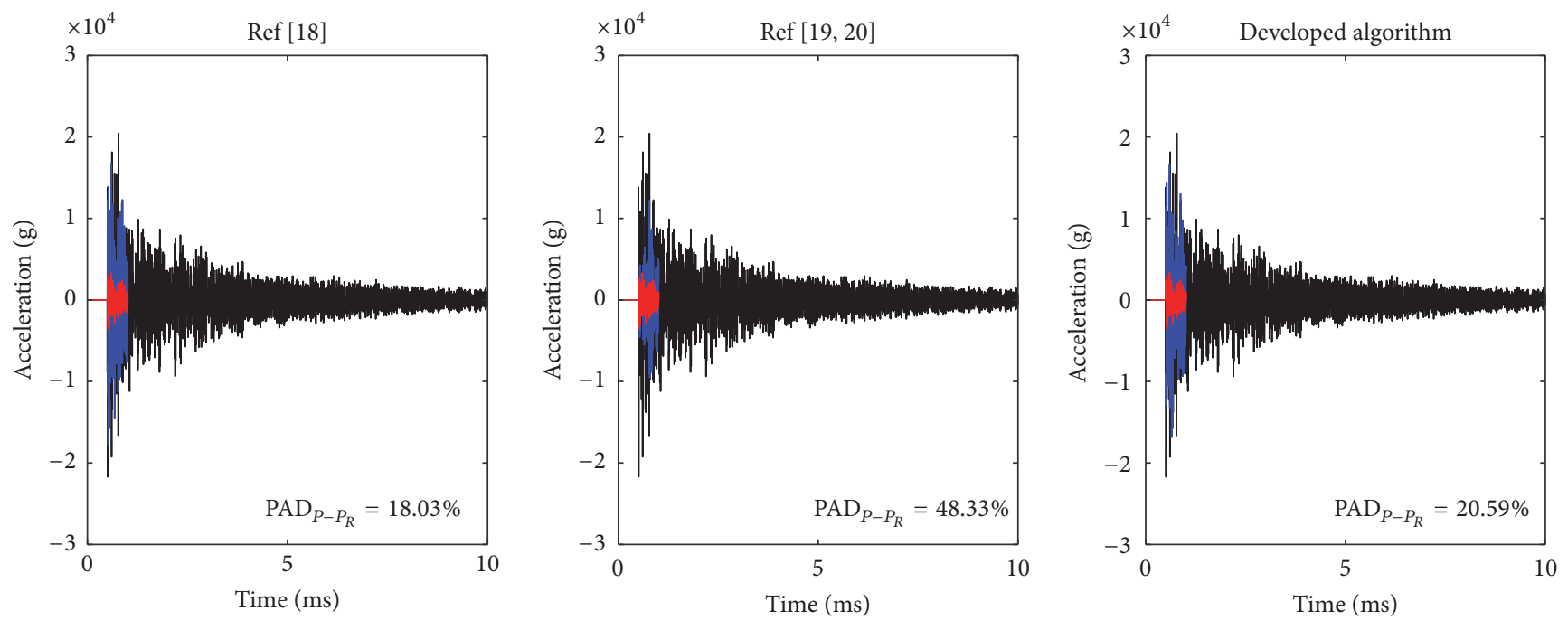

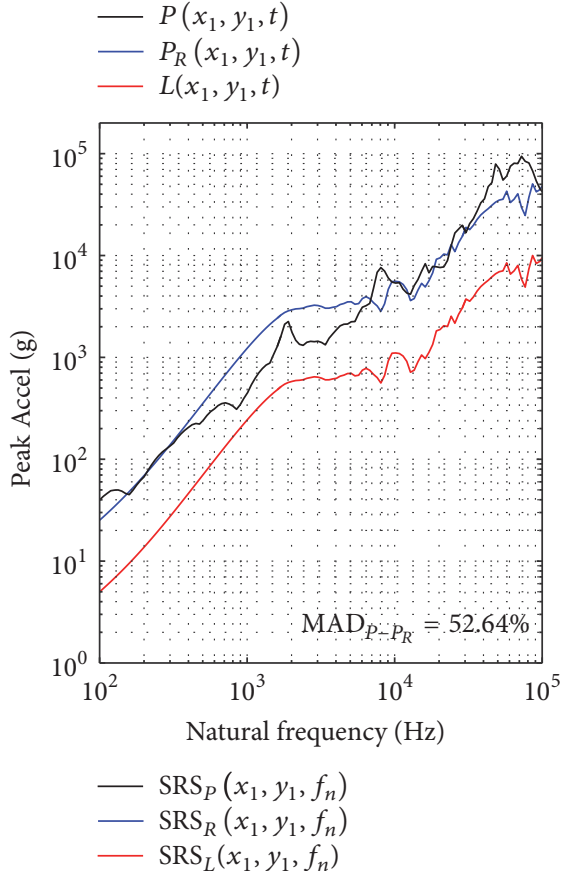

(a)

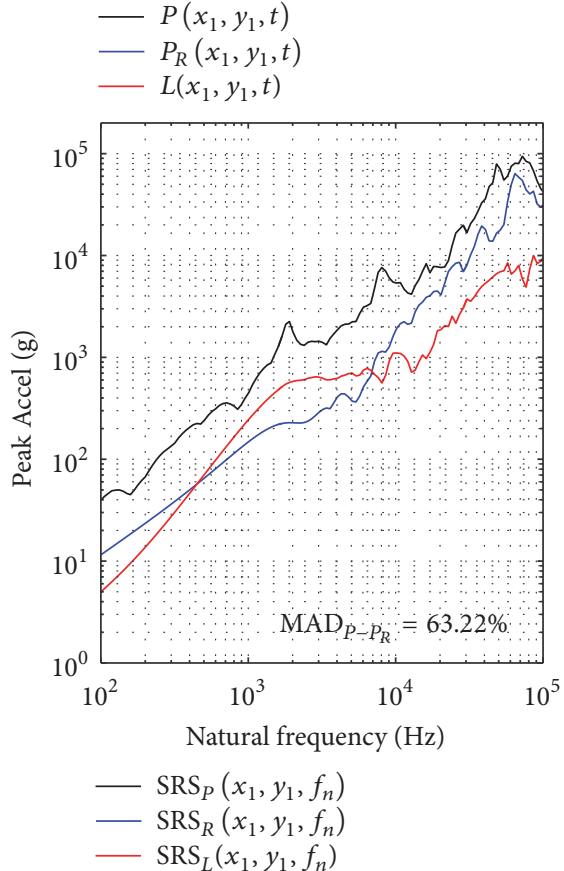

(b)
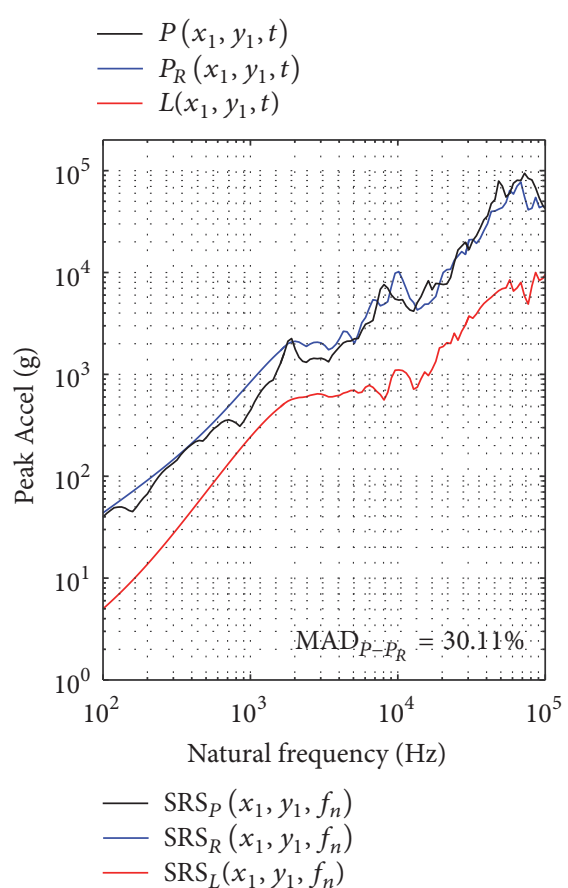

(c)

FIGURE 26: Comparison of reconstruction results of pyroshock on the disk type specimen at the verification point. (a) Ref [18]. (b) Ref [19, 20]. (c) The algorithm proposed in this paper. 
the real pyroshock. At the verification point, the time domain signal was reconstructed with an averaged PAD of $20.21 \%$ and the SRS was reconstructed with an average MAD of $25.86 \%$. This was a remarkably improved result compared to the developed pyroshock reconstruction system in [1820]. Additionally, according to [21], the repeatability of the pyroshock obtained through the same pyro device in the same structure had a MAD of $19.6 \%$. Considering this fact, the pyroshock reconstruction algorithm developed in this paper provided sufficiently reliable reconstruction results. The developed system can be used to determine the most suitable location for installing electronic equipment with a specific resonance frequency. In addition, it can be used to check the propagation path of pyroshock and effectively reduce the pyroshock transmitted to the structure. To reduce the economic burden caused by the pyro device, the developed system can be applied to the evaluation of the multi-explosive induced pyroshock using only the single pyro device test by applying the wave superposition principle. In addition, it is expected that the iterative signal decomposition and synthesis method proposed in this paper can be used widely because it effectively removes the stop band effect caused by the signal decomposition process using Butterworth filter.

\section{Conflicts of Interest}

The authors declare that there are no conflicts of interest regarding the publication of this paper.

\section{Acknowledgments}

This research was supported by the Space Core Technology Development Program (Grant no. 2013-042548) and by the Research Grant (PMD) of the Agency for Defense Development and Defense Acquisition Program Administration of the Korea government.

\section{References}

[1] J.-R. Lee, C. C. Chia, and C.-W. Kong, "Review of pyroshock wave measurement and simulation for space systems," Measurement, vol. 45, no. 4, pp. 631-642, 2012.

[2] M. G. Ryschkewitsch, "Pyroshock test criteria," NASA Technical Standard NASA-STD-7003, NASA, Washington, DC, USA, 2011.

[3] IEST-RP-DTE032.2, Pyroshock Testing Techniques, Institute of environmental sciences and technology, 2009.

[4] E. Fillippi, H. Attouoman, and C. Conti, "Pyroshock simulation using the alcatel etca test facility, in Launch vehicle vibrations," in Proceedings of the 1st European conference, CNES, Toulouse, France, 1999.

[5] C. J. Moening, "Pyrotechnic shock flight failures," in Proceedings of the ES Pryotechnic shock tutorial program, 31st Annual technical meeting, Inst. Environ. Sci., UK, 1985.

[6] L. J. Bement and M. L. Schimmel, "A manual for pyrotechnic design, Development and qualification," Tech. Rep., 1995.

[7] C. M. Harris and A. G. Piersol, Harris' Shock and Vibration Handbook, McGraw-Hill, 5th edition, 2002.

[8] K. Y, "Chang, V-Band separation shock characteristics, Jet propulsion laboratory," California institute of technology, 2004.
[9] S. L. Mayers, B. B. Beard, R. K. Smith, and A. Patterson, Ares I stage separation system design certification testing, 2009.

[10] E. Filippi, "Development of the alcatel etca pyroshock test facility, European conference on spacecraft structures," vol. 1, Braunschweig, Germany, 1999.

[11] D. Wattiaux, O. Verlinden, C. Conti, and C. De Fruytier, "Prediction of the vibration levels generated by pyrotechnic shocks using an approach by equivalent mechanical shock," Journal of Vibration and Acoustics, vol. 130, no. 4, Article ID 041012, 2008.

[12] N. Davie and V. Bateman, "Pyroshock simulation for satellite components using a tunable resonant fixture - phase 2," Tech. Rep. SAND-93-2294, 1997.

[13] J. Lee, D.-H. Hwang, J.-K. Jang et al., "Pyroshock Prediction of Ridge-Cut Explosive Bolts Using Hydrocodes," Shock and Vibration, vol. 2016, Article ID 1218767, 2016.

[14] R. Velmurugan and E. M. Najeeb, "Study of far-field pyroshock responses of composite panels," Journal of Vibration and Acoustics, vol. 136, no. 3, Article ID 031014, 2014.

[15] X. Wang, Z. Qin, J. Ding, and F. Chu, "Finite element modeling and pyroshock response analysis of separation nuts," Aerospace Science and Technology, vol. 63, pp. 380-390, 2017.

[16] Y. Mao, H. Huang, and Y. Yan, "Numerical techniques for predicting pyroshock responses of aerospace structures," Advanced Materials Research, vol. 108-111, no. 1, pp. 1043-1048, 2010.

[17] D. Lee, J. Han, H. Jang, S. Woo, and K. Kim, "Shock response prediction of a low altitude earth observation satellite during launch vehicle separation," International Journal of Aeronautical and Space Sciences, vol. 11, no. 1, pp. 49-57, 2010.

[18] J.-R. Lee, J.-K. Jang, M. Choi, and C.-W. Kong, "Visualization and simulation of a linear explosive-induced pyroshock wave using Q-switched laser and phased array transducers in a space launcher composite structure," Optics \& Laser Technology, vol. 67, pp. 12-19, 2015.

[19] S. Y. Chong and J.-R. Lee, "Pointwise Explosive-Induced Pyroshock Wave Prediction Based on Numerical Conditioning of Laser Shocks," Experimental Mechanics, vol. 54, no. 9, pp. 1651-1671, 2014.

[20] S. Y. Chong, J. R. Lee, and C. W. Kong, "Shock response spectra reconstruction of pointwise explosive-induced pyroshock based on signal processing of laser shocks," Shock and Vibration, vol. 2014, Article ID 695836, 14 pages, 2014.

[21] J. E. Alexander, "Shock response spectrum - a primer," Sound and Vibration, vol. 43, no. 6, pp. 6-15, 2009.

[22] T. Irvine, "An introduction to the shock response spectrum," 2012. 


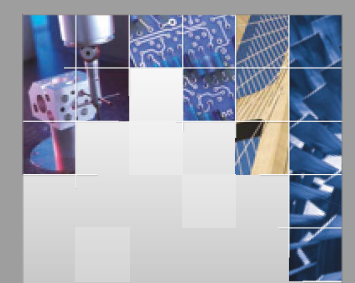

\section{Enfincering}
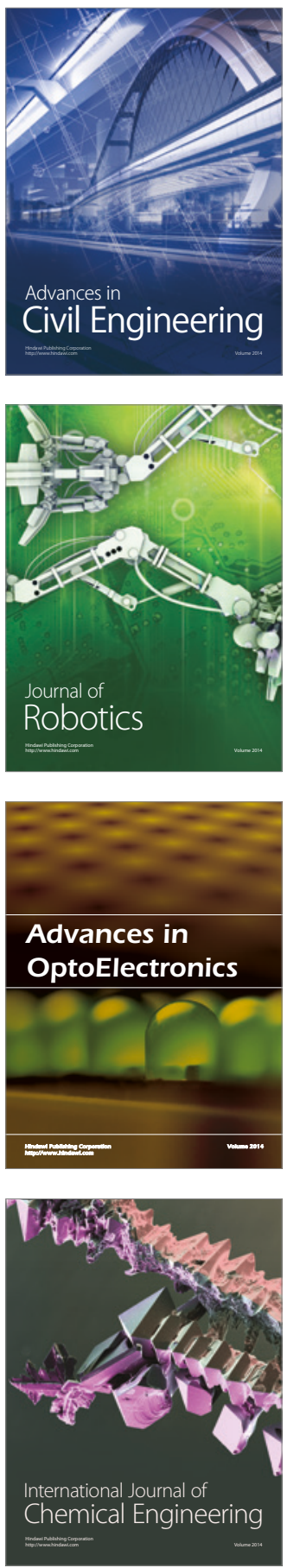

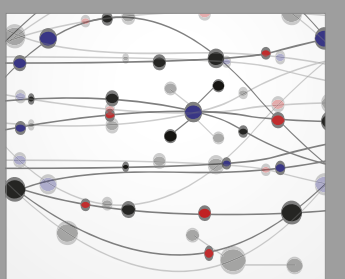

The Scientific World Journal

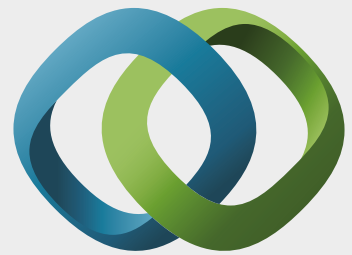

\section{Hindawi}

Submit your manuscripts at

https://www.hindawi.com
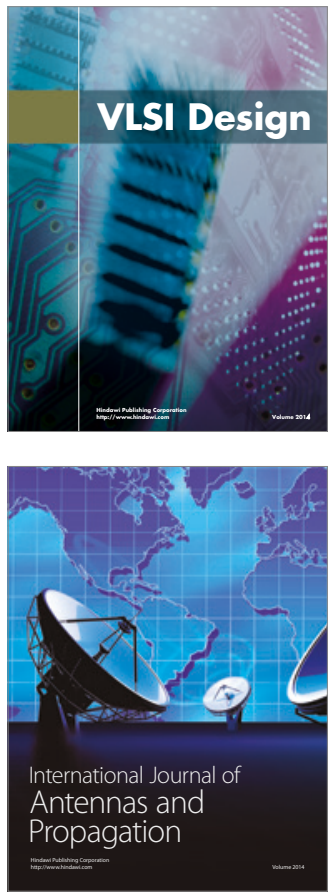

\section{Rotating}

Machinery
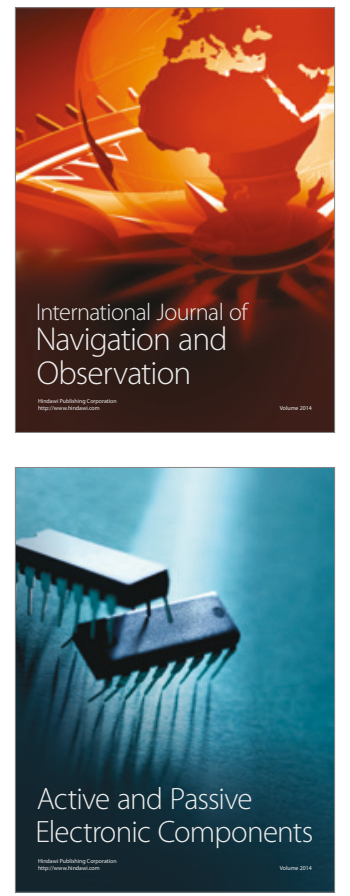
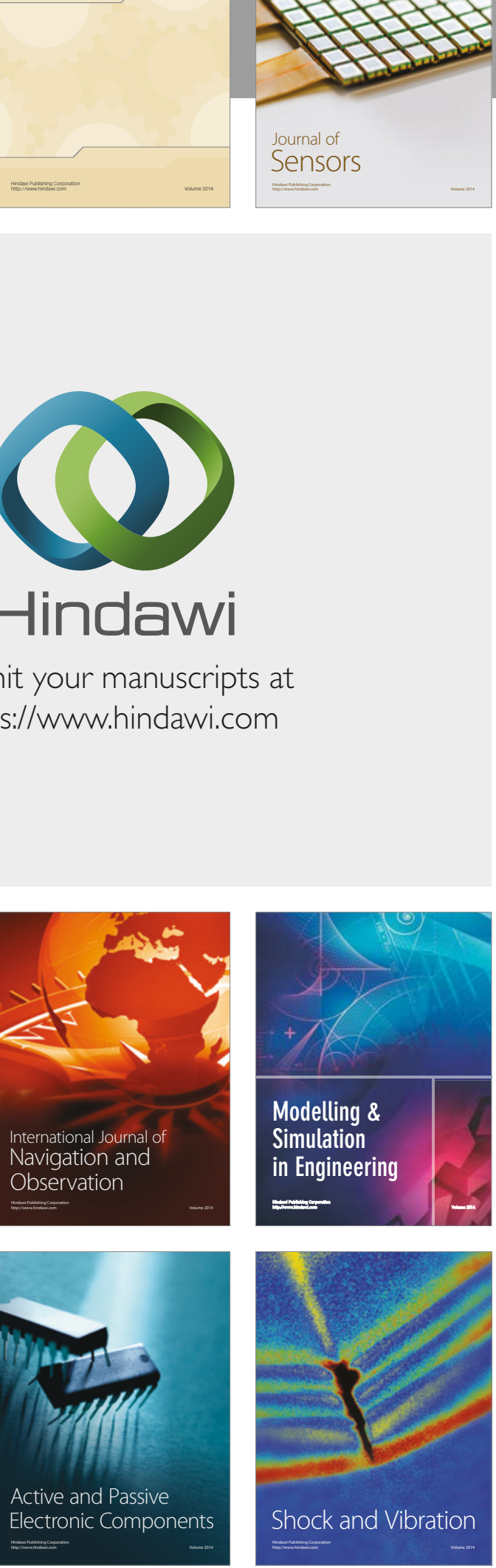
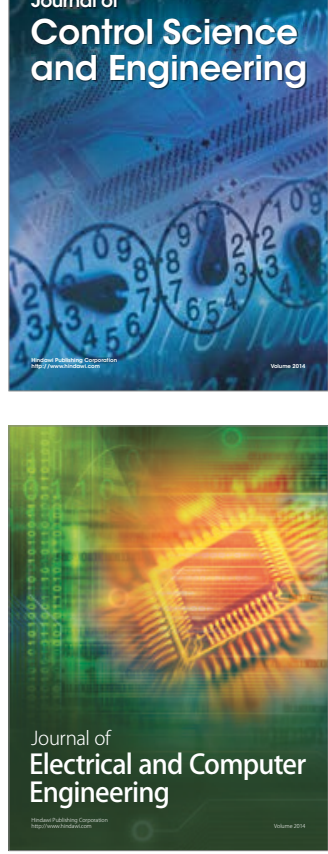

Distributed

Journal of

Control Science

and Engineering
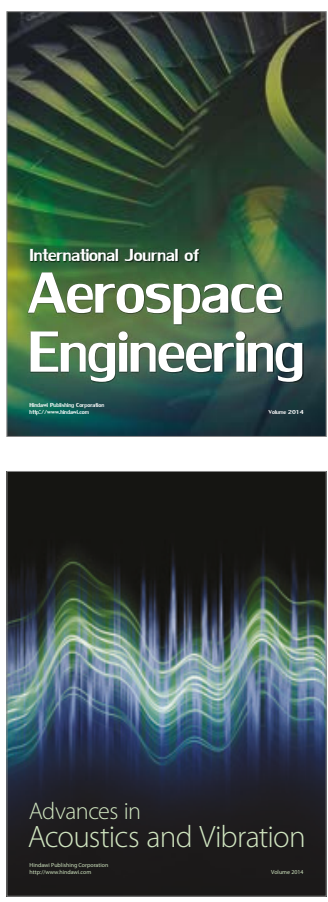

Sensor Networks 